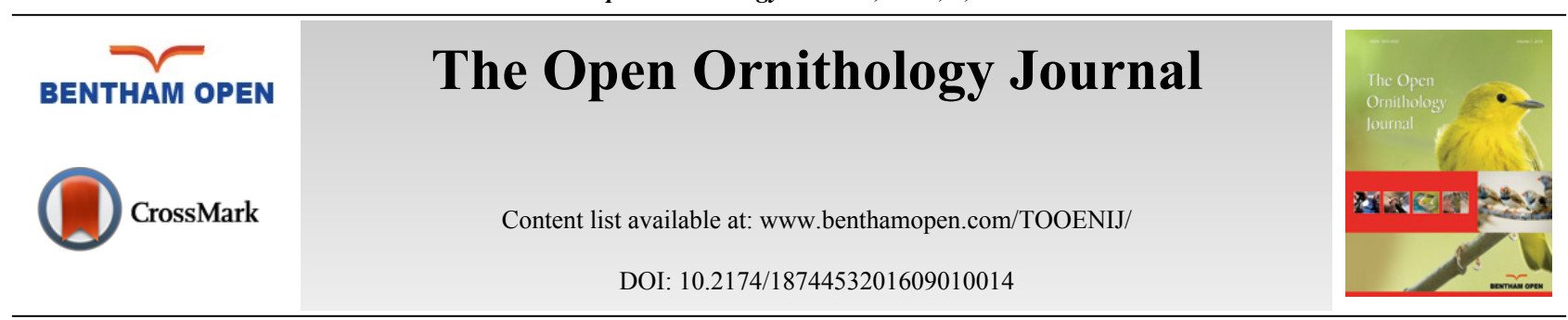

\title{
FANTASY VS REALITY: A Critique of Smith et al.'s Bird Origins
}

\author{
Alan Feduccia ${ }^{*}$ \\ Department of Biology, University of North Carolina, Chapel Hill, North Carolina 27599-3280, United States of \\ America
}

\begin{abstract}
Adherents of the current orthodoxy of a derivation of birds from theropod dinosaurs, criticize the commentary by Feduccia (2013, Auk, 130) [1 - 12] entitled "Bird Origins Anew" as well as numerous papers by Lingham-Soliar on theropod dermal fibers, using numerous mischaracterizations and misstatements of content, and illustrate their own misconceptions of the nature of the debate, which are here clarified. While there is general agreement with the affinity of birds and maniraptorans, the widely accepted phylogeny, advocating derived earth-bound maniraptorans giving rise to more primitive avians (i.e. Archaeopteryx), may be "topsyturvy." The current primary debate concerns whether maniraptorans are ancestral or derived within the phylogeny, and whether many maniraptorans and birds form a clade distinct from true theropods. Corollaries of the current scheme show largely terrestrial maniraptoran theropods similar to the Late Cretaceous Velociraptor giving rise to avians, and flight originating via a terrestrial (cursorial) "gravity-resisted," as opposed to an arboreal "gravity-assisted" model. The current dogma posits pennaceous flight remiges in earth-bound theropods having evolved in terrestrial theropods that never flew. As part of the orthodoxy, fully feathered maniraptorans such as the tetrapteryx gliders Microraptor and allies, are incorrectly reconstructed as terrestrial cursors, when in reality their anatomy and elongate hindlimb feathers would be a hindrance to terrestrial locomotion. The same is true of many early birds, exemplified by reconstruction of the arboreally adapted Confuciusornis as a terrestrial predator, part of the overall theropodan scheme of birds evolving from terrestrial dinosaurs, and flight from the ground up. Both sides of this contentious debate must be constantly aware that new fossil or even molecular discoveries on birds may change current conclusions.
\end{abstract}

Keywords: Bird origins, cladistic, flight origins, maniraptoran, phylogenomics, theropod.

\section{INTRODUCTION}

Disagreement on bird origins intensified following the 1998 declaration by Nature editor Henry Gee that "The debate is over, birds are living dinosaurs [1]." The debate continued in The Auk beginning with a perspective article by Prum [2,3] entitled "Are current critiques of the theropod origin of birds science?" in which he comments "Ornithologists should let these unworthy and unscientific arguments fade into scientific history [3]," and continues now with a reply to "Bird origins anew," [4] by Smith et al. [5], that mischaracterizes not only the paper in question but the entire debate. According to Smith et al. [5] the burden of proof falls on those who find faults with the current orthodoxy of the dinosaurian origin of birds, but many of their salient tenets represent extraordinary claims, and rest on faulty evidence. Carl Sagan is noted for his now classic axiom, "Extraordinary claims require extraordinary evidence," but importantly, he also cautioned that extraordinary claims require skepticism and imagination, both. "Imagination will often carry us to worlds that never were. But without it we go nowhere." But perhaps more importantly, "Skepticism enables us to distinguish fancy from fact, to test our speculations [6]." With respect to the current advocated unchallengeable orthodoxy of paleontology, that birds are living dinosaurs, much of the evidence foundational to the new field, including protofeathers, was never based on any extraordinary evidence, but rather appears to accommodate provisional cladograms, and now most studies exhibit a disturbing trend, to simply verify what is thought to be already known [7 - 9]. As Sir Karl Popper emphasized: "It is easy to obtain confirmations, or verifications, for nearly every

\footnotetext{
* Address correspondence to this author at the Department of Biology, University of North Carolina, Chapel Hill, North Carolina 27599-3280, United States of America; E-mail: feduccia@bio.unc.edu
} 
theory--if we look for confirmations [10]. " The founder of modern geology Charles Lyell was emphatic that science must probe behind superficial appearance, often to combat the "obvious" interpretation of the phenomenon in question [8]. In that sense, in response to Smith et al. [5], cladistics should be a well-received, but a skeptical beginning, not the end of the phylogenetic analysis: "cladistics should not become the new 'authority' [11]." The question therefore is which side of the debate has become mired in the world of imagination? And, is the current paleontological unchallengeable orthodoxy "birds are living dinosaurs" a simplification far beyond the available evidence, largely the result of a verificationist approach [7]? Here I shall refrain from the typical point-counterpoint rejoinder, and concentrate instead on the truly salient aspects of the debate. Many points made by Smith et al. [5] concern topics not even covered in The Auk perspective [4], or are dramatic mischaracterizations; and a number are offered as straw men to serve as obfuscation and foils to the real issues. Indeed, Smith et al. [5] seem to be trying to rebut almost anything they perceive Feduccia and colleagues have ever said contrary to the current orthodoxy of the field, which is constantly evolving. A vivid example of this obfuscation is noting that I cite Triassic bird tracks from Argentina, now shown to be of Eocene age. However, the study is not in the perspective, and most importantly I corrected the age [12] when contrary evidence was published and corresponded with the authors. The existence of putative protofeathers will be covered in a separate paper by T. Lingham-Soliar. There is no current compelling structural or biological scientific evidence for these structures in birds or dinosaurs, extant or extinct; and, there is no evidence for melanosome-based color of the theropod Sinosauropteryx.

Of note here is that the evidence on which Gee's 1998 proclamation, "the debate is over," [1] was derived, has recently been falsified, by showing that Caudipteryx, the taxon in question, was derived from flying ancestry, likely of avian status, and therefore pennaceous flight remiges evolved in an aerodynamic context [13], certainly not in earthbound dinosaurs. In addition, as we shall see, other major claims by Smith et al. [5] have also been recently questioned or falsified, including: an ancient origin of modern bird orders, supported by many of the Smith et al. authors ((as opposed to Feduccia's post K-Pg explosive "Big bang" [12]), now falsified by Jarvis et al. [14]; questions raised on bird genomes having evolved from theropod dinosaurs (Wright et al. [15]); the WAIR hypothesis for avian flight origin (falsified by Evangelista et al. [16] and elsewhere [8]); and color in a dinosaur (falsified by Lingham-Soliar [17]), to mention a few. Finally, as we shall see, Smith et al. [5] are at fault for most of the same supposed transgressions which they attribute to Feduccia [4], especially the use of key characters. Most importantly, however, the premise of the Smith et al. [5] paper is seriously in error, as I have noted time and time again [4, 8, 9, 13] that whatever microraptors are, so too are birds; therefore the affinity of birds and maniraptorans, the major thrust of the Smith et al. [5] paper, is not in question.

\section{Mischaracterizations and Errors by Smith et al. [5]}

\section{Archosaur Straw Man}

Current advocates of the predominant orthodoxy of a dinosaur origin of birds, and ground-up flight, claim that those in opposition support an ancestor such as Longisquama, but such an assertion is patently false and an egregious mischaracterization of the debate. For example, Smith et al. [5] claim that Feduccia supported the Triassic arboreal parachuter Longisquama as ancestral to birds; this assertion is simply erroneous; and most disturbingly, Longisquama is not even mentioned in the paper in question [4]. However, most who have studied the specimen, including myself ((having studied the single skeletal specimen in Moscow in 1982 (with feather expert Peter Stettenheim) and Kansas in 1999, with a group that included two distinguished Russian paleontologists)), find Longisquama a most interesting Triassic reptile [8], one of many early experiments in flight, but emphatically not an avian ancestor: As I stated in 2012, "The scales of Longisquama were not likely progenitors of avian feathers, but the specimen does illustrate that during the Late Triassic there was tremendous experimentation with featherlike scales in basal archosaurs presumably before the advent of feathers [8]." The best candidate to date approximating a putative avian ancestor among the predinosaurian groups, the scansoriopterids, are tiny, arboreal trunk-climbers and gliders, typified by Scansoriopteryx (=Epidendrosaurus) from the mid-Jurassic of China [18] (Fig. 1). Originally described as coelurosaurian theropods, cladistic analyses typically place the clade at the basal to the avian lineage [19 - 21], and our studies [18], using digital Keyence microscopy, show that it was a trunk-climbing archosaur and not a theropod, but it has some remarkable birdlike characters, including a tetrapteryx bauplan, avian feathers, an avian hand with a semilunate carpal element, a reversed hallux, a propatagium, and a non-dinosaurian pelvis, acetabulum and femur. It was clearly a four-winged glider of avian affinity, and I predict other scansoriopterids such as Epidexipteryx will also turn out to be similar in anatomy and habits [20]. As noted elsewhere [4], despite the absence of preserved flight remiges in Epidexipteryx, they 
were likely present in life, and there are many cases in fossil birds (e.g. Lower Cretaceous Longipteryx), where body feathers, but not flight remiges, are preserved [8]. Most interestingly, although scansoriopterids are cladistically slotted as coelurosaurian theropods at the base of Aves in a number of analyses [21], they are totally devoid of theropod skeletal characters, not even dinosaurian characters. Although the specimen of Scansoriopteryx [18] is a juvenile, similar fossils of juvenile dinosaurs and juvenile ratite birds all show the salient bony characters of the adult [22, 23]. It is certainly a very birdlike archosaur, at the base of the avian lineage, and Chinese workers have recognized this close affinity; they are are more similar to basal birds than to Archaeopteryx in many of their derived cranial features, and the general cranial anatomy is also seen in the oviraptorosaurs and the euenantiornithine Eoenantiornis buhleri [pers. observation]. S.A. Czerkas has noted [24], "The phalanges of digit III become progressively shorter distally. . . Despite the extreme total length, this pattern of progressive reduction is consistent with representing the ancestral condition found in Pseudosuchia ..." If scansoriopterids had been discovered at the turn of the $20^{\text {th }}$ century there would have been little doubt that birds derived from arboreal gliders that were not dinosaurs.
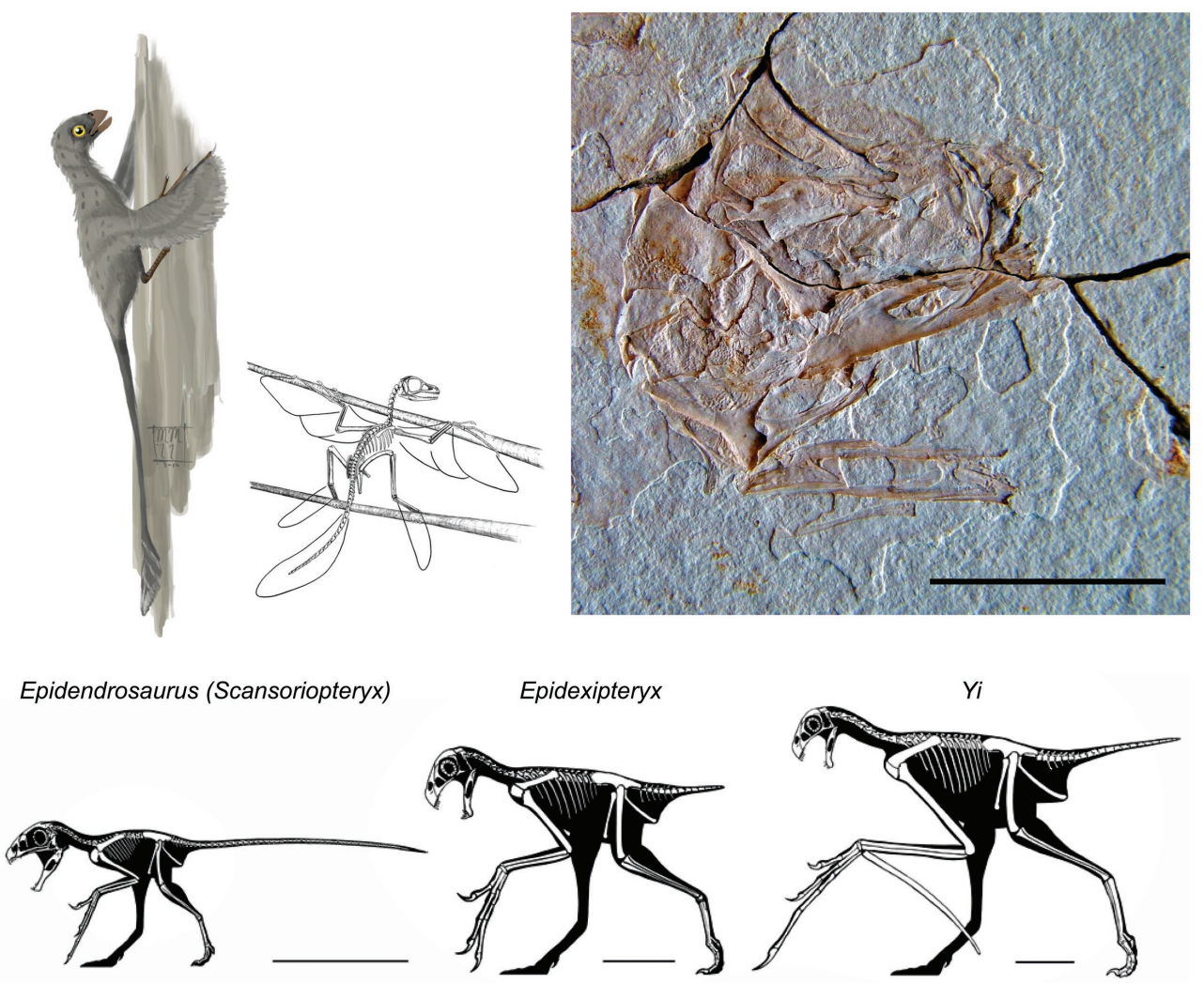

Fig. (1). Reconstruction of Scansoriopteryx (=Epidendrosaurus), upper left, as a trunk-climbing glider; subsequent study of the specimen using Keyence microscopy showed hind-limb wings, providing new evidence for tetrapteryx gliding (see inset sketch by S. A. Czerkas). Lower, reconstructions of currently known scansoriopterids as terrestrial cursors, a reconstruction that is highly improbable and dictated by attempts to "accommodate the cladograms" indicating direct "dinosaur' descendancy. Their pelves are not adapted for cursorial habits and in Scansoriopteryx the acetabulum is nearly closed, with no supra-acetabular crest. The femur, too, is not that of a bipedal cursor [see 18]. The other genera are quite similar in pelvic anatomy. Upper right, Digital Keyence image of the skull of Scansoriopteryx, similar to oviraptorosaurids, which is not that of a dinosaur, and the teeth are, like those of Epidexipteryx and $Y i$, simple peg-like teeth constricted at the base, similar to those of oviraptorosaurs and Mesozoic birds. Scansoriopteryx, upper left, reconstruction ... By Matt Martyniuk, 2011 [CC: (http://creativecommons.org/licenses/by/3.0)], via Wikimedia Commons. Digital Keyence microscopy [see 18] image of skull, counterslab, courtesy Stephen A. and Sylvia J. Czerkas; copyright Stephen A. Czerkas; Institute of Geology, Chinese Academy of Sciences, CAGS02-IG-gausa-1/DM 607. Lower, left to right, reconstructions of Epidendrosaurus (=Scansoriopteryx), Epidexipteryx, and Yi, by Lida Xing, in: Padian, K. [26]; Reprinted by permission from Macmillan Publishers Ltd: Nature. Padian K. Dinosaur up in the air. Nature (News and Views) 2015; doi:10.1038/nature14392 (copyright 2015). Scale bars: skull, $1 \mathrm{~cm}$; lower images, $5 \mathrm{~cm}$.

More recently, a strange addition to the scansoriopterids, Yi qui ("strange wing") has been described from the same, presumably mid-Jurassic deposits $[25,26]$. The incomplete skeleton of a single adult was a small, likely arboreal animal, but the elongated third finger helped support a membranous gliding patagial membrane which was also 
supported by a long, bony strut attached to the wrist. Such flight modifications were unknown before, and the wing was possibly bat-like. It may be that in these forms flight patagia combined with feathers in a manner not yet fully understood. This specimen may also indicate that the elongate finger of Scansoriopteryx (Epidendrosaurus) was involved with some type of patagial membrane that is not preserved, and a propatagium is known in Scansoriopteryx, a strong indication of some level of flight [18]. To date the Jurassic scansoriopterids, combined with the early maniraptoran microraptors, archaeopterygids, anchiornithids [27] and allies, represent the closest approximation we have for avian ancestry [18], and they were very likely all "wing-assisted trunk climbers" [26 - 29] and gliders [8, 28, 29]. The reconstruction of currently-known scansoriopterids as terrestrial mini-theropods (Fig. 1) is unjustified on the basis of anatomy. These animals are devoid of any salient theropod characters.

\section{Weak Data for Dramatic Conclusions}

Many find such cladistic analyses like that of Turner et al. [30], based on very scrappy fossil material and dramatically incomplete data sets [4 (Table 1)] incapable of placing a Late Cretaceous dromaeosaur at the heart of the issue of theropod miniaturization and flight origins, which must have occurred no later than the Early Jurassic. Indeed, some $65 \%$ of their 474 characters in the matrix are question marks, rendering the analysis highly dubious.

In Turner's et al. own words: “Graciliraptor is based on a single specimen composed of a partial maxilla, nearly complete limbs, and 10 partial tail vertebrae; Mahakala is also based on scant material, including some skull bones, vertebrae, limb bones, and parts of the pelvis and shoulder girdle [30]."

In terms of proposals involving miniaturization, if any heterochrony is involved [31], the already foreshortened forelimbs of early dinosaurs would be even shorter, as the phenomenon usually affects all aspects of the phenotype, and paedomorphosis causes a disto-proximal attenuation of the anterior appendages, beginning with the hand. Thus, instead of lengthening the arm and hand towards the avian condition, the result would be just the opposite. If the result were, "paedomorphic skulls with reduced snouts but enlarged eyes and brains [32]," one would find reptiles more similar to Triassic archosaurs than theropods [33]. Bearing on this aspect of the debate, Hwang and colleagues described additional skeletons of the small arboreal, tetrapteryx dromaeosaur Microraptor, concluding that dromaeosaurs are monophyletic and that Microraptor is the sister taxon to other dromaeosaurs. Together with troodontids, microraptors form a monophyletic Deinonychosauria, the sister group of the Avialae [34]. They also found small size primitive for the group (my italics). Interestingly, Microraptor proved very similar to the troodontid Sinovenator, and each a primitive member of its respective, closely related group, close to the deinonychosaurian split. There is clearly much more missing from our knowledge of early avian evolution.

\section{Salient Features of the Debate}

Two salient points form the foundational core of the current orthodoxy of the field, the BMT (birds are maniraptoran theropods) phylogeny, and flight origins from the ground up (which concerns the de Beer, Huxley and Lowe debate $[8,35]$ ), which is also an inextricable aspect of the current bird-dinosaur dogma.

Those who think questioning the current orthodoxy is an attack on phylogenetic systematics are deluded and have not read "Riddle of the feathered dragons" [8] or recent papers by Lingham-Soliar (citations in [8]). The book includes some 26 cladograms (more than in Chiappe's book on bird evolution [36]), with comments on cladistics being the best approach at present for deciphering the new Chinese fossils. Numerous instances where cladistic analyses are not confirmed by modern molecular phylogenomics [ 8 chapters 5/6], will not be reiterated here, and the criticism extends not only to cladistics but total reliance on morphology in general, particularly where massive convergence is involved (loons and grebes [37]; stiff-tailed ducks [38], cases of paedomorphosis (particularly ratites) [39], moa-nalos [40]), cases where skulls were discovered after the postcranial skeleton (dromornithids [41]), and many others where convergent morphology masked the identity [8]. Indeed, in a recent whole genome analysis, numerous morphological convergences were noted [14]: "the Columbea and Passerea clades appear to have many ecologically driven convergent traits that have led previous studies to group them into supposed monophyletic taxa ... These convergences include the foot-propelled diving trait of grebes in Columbea with loons and cormorants . . . in Passerea, the wading-feeding trait of flamingos in Columbea, with ibises and egrets in Passerea ... and pigeons and sandgrouse in Columbea with shorebirds (killdeer) in Passerea ... These long-known trait and morphological alliances suggest that some of the traditional nongenomic trait classifications are based on polyphyletic assemblages." Among the more interesting disparities between cladistic and phylogenomic studies concerns ratites, which have been argued cladistically to all be derived from a single ancestor deep in the Cretaceous and as flightless birds walked to their respective continents [42, 
43]; yet, any number of phylogenomic studies show that the various members evolved the flightless condition independently [8, chapter 5 for lengthy discussion].

Organ and Edwards argued for a bird descent from theropods based on the possession in both groups of small genomes [44]. Yet, genome size is poorly understood at this point, and although the studies have been most interesting, the true meaning of genome size remains unclear. Assuming the correlational assay of cell size and genome size holds, one would need to make much more extensive comparisons, and the issue is compounded by the fact that strong-flying birds (swifts and hummingbirds) [15] have particularly small genomes, and likewise small genome size is characteristic of both bats and pterosaurs [45].

The current studies base dinosaur genome size on the size of bony osteocytes, an unproved assumption, conflate early birds (e.g.Caudipteryx) and theropods in their comparisons (which are not extensive and inadequate), but fail to examine a variety of modern bird bones for osteocyte size comparisons. Too, the differences between ornithischians and theropods is slight, and most importantly, a recent study shows convincingly that "metabolic 'engines' of flight drive genome size reduction in birds," thus provisionally questioning the Organ/Edwards hypothesis [15]. The rate of energy use is implicated as the key driver of repeated evolutionary reductions in avian genome size, and certainly not their affinity with earth-bound theropod dinosaurs.

Among the pitfalls of the currently practiced methodology of cladistics are the following outlined by James and Pourtless [7]: unjustifiable assumptions of homology, inadequate taxon sampling, insufficiently rigorous application of cladistic methods, lack of statistical evaluation, verificationist arguments, and introduction of ad-hoc auxillary hypotheses. I would add that still another serious overlooked problem is massive co-correlation of characters from single character complexes, such as a hind limb characterized by a mesotarsal joint and obligate bipedalism, which might encompass literally dozens of skeletal apomorphies, aligned with no distinction with major key characters. Mayr has criticized the current practice, in particular an analysis using 2,954 characters [37], as producing, "a low ratio of phylogenetic signal to 'noise' in the data [46]." As a consequence the current use of massive characters in cladistic analyses is strikingly similar to the phenetic approach of the 1970s which grouped clusters by overall similarity, often blending convergence with true relatedness. Such an approach is not all bad, but as has been pointed out, it may be asking too much of morphology to tell us both the genealogy of organisms and what they look like [47]. That the demonstrably convergent loons and grebes slot as a valid clade based on 2,954 characters [37], but refuted by embryology and almost every molecular and genomic analysis [8, 14, 39], should be a cautionary note to all using overall similarity to assess relationships.

\section{Key Characters}

While today's cladists typically revolt at the use of key characters [1], it is notable that fossils such as the rauisuchian Postosuchus and paracrocodilian Effigia (poposaurid), theropod-like Triassic archosaurs, possibly paraphyletic (formerly pseudosuchian thecodonts), became amazingly convergent on theropods. Effigia was studied by Nesbitt [48] who showed that it was not a crocodilomorph, but an ornithomimid-like suchian (see also [49]; and Chatterjee [50] described Postosuchus as a facultatively bipedal, carnosaur-like suchian, showing that, as Nesbitt and Norell [51] note, "some of the Late Triassic suchians may have occupied similar adaptive zones to subsequent clades of dinosaurs," showing a trend in Late Triassic lineages towards occupying the bipedal predatory niche later dominated by theropods. Yet, importantly, these forms are excluded from cladistic analyses of theropods solely because of an $a$ priori decision based on a single key character, the crocodilian-like ankle joint; otherwise, Postosuchus would easily ratchet up to the ceratosaur level in any cladogram (Fig. 2).

Likewise, one might ask also why so much attention has been given to the homology of the avian digits if this character complex is no more important than other skeletal apomorphies. The reason is clear: "Early in the debate (1984) it was noted that if one key synapomorphy were falsified, it would reduce all the others to the status of parallelism or homoplasy [52]. With that in mind it is of note that the latest two major papers on avian digital homology find that the avian hand is indeed, in contrast to theropods that retain digits I-II-III, composed of digits II-III-IV [53, 54], as first shown from by the discovery of digit I in ostrich using comparative embryology [8, 55]. All sides of the debate agree that the avian embryonic digital condensations are pentadactyl and show dominant digits II-III-IV, so Indeed, if a "homeotic frame shift" had occurred [56], to somehow transmute the embryonic digits to I-II-III, as in dinosaurs in the evolution of the avian hand, the implications would be huge. If such shifts are common in vertebrate evolution then one would never know if apomorphies used in analyses are real or the result of such unknown change. 


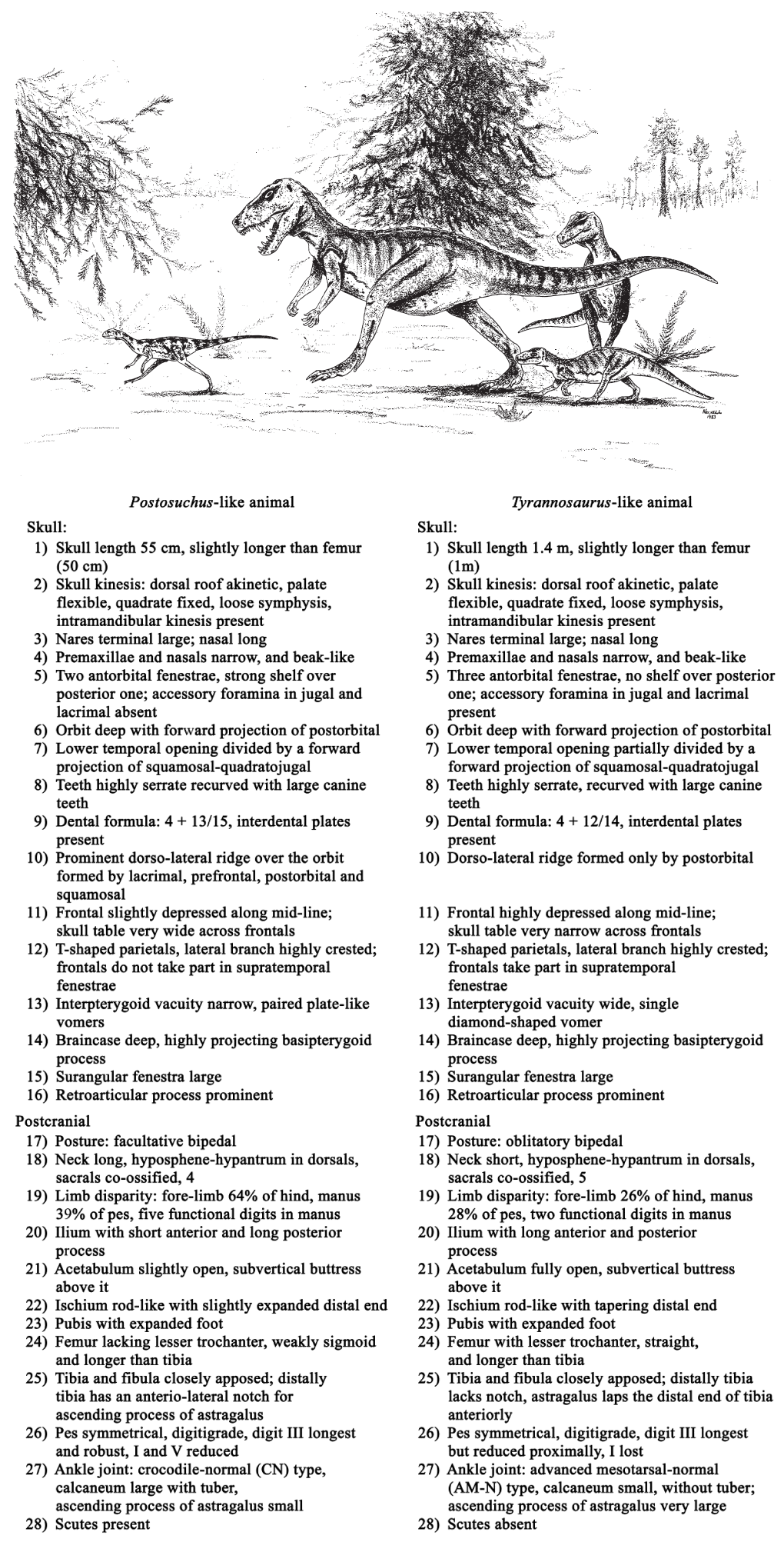

Fig. (2). Above, the Late Triassic rauisuchian Postosuchus, originally described as a theropod dinosaur. Below, skeletal characters of the Triassic archosaur Postosuchus (formerly called a thecodont), compared to tyrannosaurids. In innumerable skeletal characters and proportions it is quite close to theropod dinosaurs, and were it not for a single character complex, the ankle, Postosuchus could easily be considered a ceratosaurian theropod [50]. Theropod convergence has also been documented in several primitive Late Triassic paracrocodilians (Effigia and Carnufex), as well as in Poposaurus, a Late Triassic pseudosuchian, described variously as a dinosaur, phytosaur and rauisuchian. Image and table from Chatterjee [50], with permission. 
Timing of identity factors occurs quite early in development, at the limb bud stage, and thus alteration of the epigenetic landscape at such an early stage would have major collateral consequences throughout development [8]. Demonstrably the avian embryonic hand offers proof of the presence of fully developed condensations for digits II-III$\mathrm{IV}$, and greatly reduced, vestigial, condensations for digits I and V, typical of the pattern of manual digital reduction for all amniote clades except dinosaurs. Čapek et al. [53] reject a homeotic shift hypothesis and argue, " that a concerted mechanism of molecular regulation and developmental mechanics is capable of shifting the boundaries of hoxD expression in embryonic forelimb buds as well as changing the digit phenotypes. Based on a distinction between positional (topological) and compositional (phenotypic) homology criteria, we argue that the identity of the avian digits is II, III, IV, despite a partially altered phenotype."

The primary question, however, is: if birds are living dinosaurs, why would such a shift have been necessary "between Allosaurus and birds" (whatever that may mean), and with no imaginable selective advantage, [56], since if birds were dinosaurs they would, of course, have had a dinosaurian hand of I-II-III. Zhou noted of Chinese maniraptorans: "If we simply compare the hands of Archaeoperyx and some maniraptoran theropods, such as Microraptor, they are almost the same in every detail, including the phalangeal formula. If we accept the 'II-III-III' for modern birds, and assume the same for Archaeopteryx, then why not accept the same conclusion for Microraptor [57]?" $\mathrm{Xu}$ et al. [25] accept a II-III-IV hand for all maniraptorans and birds; I believe the evidence supports such a conclusion. Another aspect of the debate on manual characters attended the early view of Archaeopteryx as having a dinosaurian III-III hand and was based on the phylogenetically unrealiable phalangeal formula of P 2,3,4. Yet, when it was discovered that the primitive oviraptorosaurid Caudipteryx, first considered a "feathered dinosaur" but also later a secondarily flightless bird [13], had an advanced avian hand and phalangeal formula of P 2,3,2, it was dismissed [8], again illustrating the trend towards a verificationist approach [7]. Thus phylogenetic analyses (cladistics) while insightful and productive as first steps, should be used to provide a scaffold and exploratory method for future comparative analyses.

Of greater concern, however, is that if homeotic frame shifts commonly occur in vertebrate and organismal history, such shifts would erode the most basic concept of embryonic connectivity and developmental fidelity in deciphering homologous structures, and would erode confidence of character use in phylogenetics.

\section{Flight Origins}

At the onset of the debate in the 1980s, the vast majority of workers in the field favored a trees-down flight origin, but paradoxically a majority also favored a dinosaurian origin of birds, which was seemingly at the time, contradictory, since all known theropods at the time were strictly earthbound. Today, with the discovery of four-winged gliders such as Microraptor, several Chinese workers, as well as Chatterjee and Templin [28, 29] have suggested a "dinosaurian trees down" eclectic model. Nevertheless most hard-core paleontologists still favor the biophysically improbable ground-up model (conta Smith et al. [5]), particularly Norell, Chiappe, and Padian and Chiappe [36, 58 - 60]. Chiappe summarized his view on flight origins, "the ancestral mode of life of birds was that of a cursorial biped [similar to Velociraptor]. Inferences about the habits of Archaeopteryx should be made within this framework and not the reverse [59]," and since then he has been trying, along with his colleague Padian, to prove ground-up flight [36, 58], Padian not only arguing that mode of flight origin for birds, but also for pterosaurs, now falsified from diverse lines of evidence [8]. Following this model the life reconstructions of early birds were rendered to accommodate the cladogram, and as a consequence the early, fully volant, arboreal birds are shown as just beginning to fly, from the ground up. This is not science (falsification), but a verificationist approach, designed to accommodate the cladogram, because all these models have proved deficient biomechanically [8, 29].

In the arboreal protoavis there is minimal energy expenditure, "gravity-assisted flight," because the organism works with gravity and drag; whereas in the cursorial model the organism works against gravity and drag, "gravity-resisted flight." Fig. (3) shows the extent of hind-limb remiges in the Early Cretaceous birdlike four-winged glider Microraptor, with the original reconstruction of Microraptor as a glider, and recent flawed life reconstructions of the tetrapteryx gliders Microraptor and Anchiornis as earth-bound theropods. Four-winged gliders are now incorrectly reconstructed as obligate bipeds, small versions of T. rex, because the cladogram shows them as "feathered dinosaurs" but they lack the pelvic structure of theropods and they are clearly not cursorial bipeds with their elongate hind-limb flight remiges.

Standing in stark contrast to almost all, including the author who studied Microraptor, Mark Norell in a NOVA program said "I wouldn't say that we know that Microraptor even was a glider, let alone a flyer [60]" He also noted, "I really get frustrated by this [argument on the origin of birds] because we shouldn't be having to deal with something 
which has been settled for 20 years. I don't know when Magellan got back from sailing around the world[in reality the Victoria returned to Spain in 1522 without Magellan, who had been killed in the Philippines], if he was frustrated, too, by people who still said the Earth was flat (ibid, pt. 2). Continuing the NOVA program narrated, "Sinosauropteryx ... 'first Chinese winged lizard.' . . . With fuzzy feathers . . . it is unlikely that it ever flew. The feathers could, however, help keep the dinosaur warm through cool nights in the temperate forest (ibid)." There is, however, no evidence of endothermy in these dinosaurs. As for microraptors, these forms were almost certainly all four-winged, trunk-climbing, tetrapteryx gliders $[29,61]$. Cursorial models for flight origins are seriously flawed and should be abandoned [8, 28, 29].

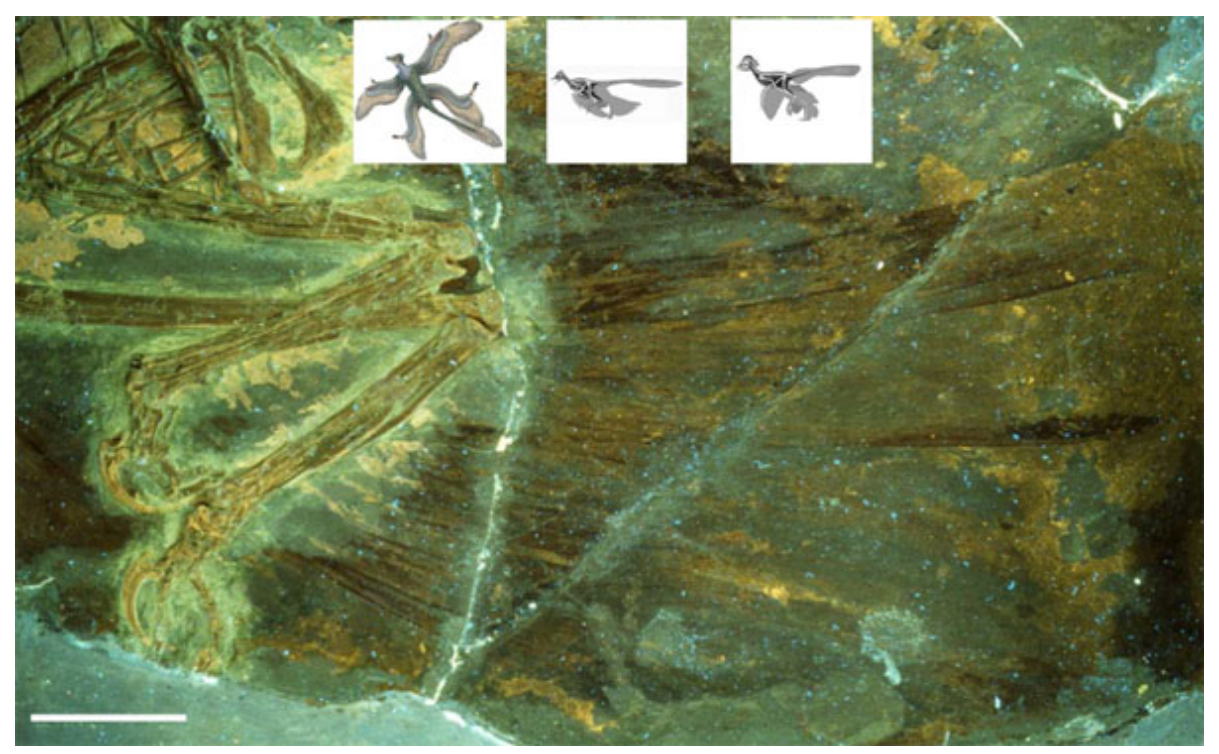

Fig. (3). Ultraviolet light photograph showing the extent of preserved hind-limb flight remiges on the tetrapteryx glider Microraptor, illustrating that it could not have been a terrestrial cursor as currently reconstructed; the elongate hind-limb remiges would have been a hindrance in terrestrial locomotion. Images inset at top show the life reconstruction of the tetrapteryx glider Microraptor from the original description [61]; (Image adapted from drawing by Portia Sloan), followed by the reconstruction advocated by the American Museum of Natural History, as an untenable cursorial predator, accommodating the cladogram, showing these forms as obligately bipedal theropods. In reality microraptors were trunk-climbing gliders as they were originally described. The third image is the midJurassic trunk-climbing glider Anchiornis, also shown as a small cursorial dinosaur [27]. Upper right image, Reprinted with permission from Macmillan Publishers Ltd: Nature. Xu X, et al. Four-winged dinosaurs from China. Nature 2003; 421: 335-340. Copyright 2003. Upper, middle and right images, Reprinted with permission from Macmillan Publishers Ltd: Nature. Dongyu $\mathrm{H}$, et al. A pre-Archaeopteryx troodontid theropod from China with long feathers on the metatarsal. Nature 2009; 461: 640-643. Copyright 2009. UV photo from Hone, DWE, Tischlinger H, Xu X, Zhang F-C. The extent of the preserved feathers on the four-winged dinosaur Microraptor gui under ultraviolet light. PLOS One 2010; 5: 9223. (Distribution under the Creative Commons License Deed, Attribution 2.5 Generic) (Scale bar $5 \mathrm{~cm}$ ).

The most popular model today, which provided the illusion for Smith et al. [5] that the field had moved on from the old arboreal $v s$ cursorial debate was that of Dial [62] and subsequent series of papers [see 8, 29] in which he introduced the WAIR ("Wing-Assisted Inclined Running") model based inappropriately on the flight ontogeny of one of the most highly derived hill-climbing quail (Alectoris), attempting to show how a putative theropod avian ancestor began to climb overhanging slopes by flapping wings before gliding down (the "ground-down" theory of Olson, [8]). The model, however, suffers from any number of insurmountable problems and has been refuted numerous times, most prominently by Senter [63], Feduccia [8], and Chatterjee and Templin [28], on a number of points, primarily the fact that avian ancestors, either theropodan or archosaurian, lacked the appropriate pectoral architecture and musculature to enact WAIR. Most recently Bock [64] argued on anatomy that urvogels like Archaeopteryx (even more true of putative archosaurian or theropodan ancestors of birds), were specialized gliders and not active flapping fliers, and Evangelista et al. [16] showed that even the ontogenetic evidence cited by Dial was critically flawed. In reality, by observing fledging ducks such as the Wood Duck (Aix sponsa) or Common Goldeneye (Bucephala clangula) jumping out of their tree nests to the ground, with wings spread out and feet laterally splayed, one could just as easily conclude that birds evolved from gliding ancestors, the most probable scenario. Concluding that ancestral birds were predominantly trunkclimbing gliders, Chatterjee and Templin [28] introduced the term "Wing-Assisted Climbing" (WAC) as an alternative 
model for flight origins based on the fact that, "Several feathered paravian coelurosaurs, exemplified by Epidendrosaurus [=Scansoriopteryx], Epidexipteryx, and Scansoriopteryx with wings suitable for climbing, became arboreal [28]." I agree with Chatterjee and Templin's general model, but disagree with their view that Epidexipteryx was flightless; all were likely four-winged gliders, as has been shown for Scansoriopteryx [4, 18]. The absence of wing feathers at this early stage of discovery is not conclusive, since feathers on the body may be selectively preserved, sometimes with no remiges [4 (Fig. 5)]. Too, while some of these early forms may appear to have been terrestrial based on claw curvature, many of the studies are seriously flawed because of: a) mischaracterization of habits of living birds, and b) use of the bony ungual to obtain measurements [65]. Characterizing galliforms as terrestrial is extremely deceiving, as the vast majority of its members, including chickens and pheasants, guans and chachalacas, turkeys and others, spend at least half their day in trees, roosting; so they are both arboreal and terrestrial. Secondly, the bony ungual is incapable of providing a veracious measure of claw curvature, which can only accurately be obtained from the keratinous sheath. Yet, Birn-Jeffery et al. stated of their recent claw study [65]: "The majority of fossil specimens lacked both the claw's keratinous sheath and any impressions of it; in these cases the ungual alone was used," thus negating their analysis. Such an approach was used earlier by Ostrom to attempt to prove that Archaeopteryx was a ground dweller [66], but his results were falsified by Yalden [67, 68]. Use of the bony ungual alone negates any results from the study, and Yalden [68] showed that in the case of Archaeopteryx, trunk climbing could be deduced by extreme curvature combined with extreme lateral compression, so multiple measures must be assessed.

Smith et al. [5] claim that the field has moved beyond the debate on whether flight originated from the trees-down, arboreal model, or by the ground-up, cursorial model, but the facts dispute their claim. This debate gained ascendency back in 1984 at the well-known Archaeopteryx conference in Eichstätt, Germany, when the issue of flight origins and bird ancestry were debated from many different angles $[8,69,70]$. At that time the consensus was that: birds were derived from coelurosaurian theropods; but, paradoxically (for the evidence then), flight originated from the trees down. As far back as several decades ago everything under consideration with respect to bird origins, including Archaeopteryx, became an earth-bound theropod, despite highly advanced arboreal features. Now, virtually all of the important basal avialans from China are incorrectly reconstructed as earth-bound theropods, despite well-developed wings with full length flight remiges, highly recurved claws and other arboreal features. Even the highly adapted arboreal bird Confuciusornis is reconstructed as an earth-bound creature seemingly using its spread wings in a predatory function, as an apparent extension of Ostrom's failed insect net model [58, 71]. Chiappe and Norell's monograph on the earliest beaked bird Confuciusornis [71] was deservedly discredited in a review by the Smithsonian's Storrs Olson [72]. In this monograph they attempt to turn this clearly arboreal flier into a terrestrial predator, conforming to the ground-up scenario: "even though millions of years had elapsed since the time of Archaeopteryx, the theropodists still seem to want all birds in the early Cretaceous to be terrestrial, as though this would somehow add strength to their requisite "'ground-up" theory of avian flight," and "if Chiappe et al., actually understand the true significance of Confuciusornis, then they have done their best to prevent it from being revealed. Their paper will stand as an exemplar of manipulation of information to conform to preconceived ideas, but it is otherwise insufficiently credible or comprehensive to constitute a lasting addition to knowledge [72]."

Finally, illustrating Ostrom's agony with having to couple his dinosaurian origin of birds with a cursorial origin of flight, he states [73]: "For obvious reasons, the arboreal theory has been favored ever since the cursorial theory was offered ... Obviously, it is more difficult to accept a 'beginning flier' fighting against gravity as it struggles to become airborne. It is much easier to accept that 'beginning flier' coasting down from an elevated perch under the power of gravity."

Smith et al. [5] and others supporting the current orthodoxy of the bird-dinosaur nexus, as noted, are quick to point out that the field has moved beyond the dichotomy of trees-down $v s$ ground-up in discussions of flight origin, largely based on Dail's failed WAIR hypothesis (ground-down theory). But this is simply not the case, as almost any museum with an exhibit on bird origins emphasizes the ground-up theory, including the British Museum of Natural History. In the USA this is especially true for the American Museum of Natural History (Fig. 4).The dominance of the ground-up model among paleontologists illustrates that Smith et al. [5] mischaracterized this aspect of the debate.

\section{Birds are Maniraptoran Theropods}

Among the most egregious mischaracterizations of the debate is that those opposing the current orthodoxy deny that birds and maniraptorans are allied. Smith et al. [5] state that birds are living dinosaurs, but I have stated many times that "whatever microraptors and Anchiornis (dinosaurs for Smith et al. [5]) are, so too are birds (Feducccia, [4, 8, 9])," that 
is, birds are maniraptoran theropods, or perhaps better stated, core maniraptorans are birds. While Smith et al. [5] correctly state that evidence is overwhelmingly convincing that birds are maniraptoran theropod dinosaurs, setting up a straw man, they fail to mention that many, like myself, who find fault with many of the arguments, agree that "birds and maniraptoran theropods" (at least core maniraptorans: oviraptorosaurs, troodontids and dromaeosaurs) are closely allied; their view that I (and colleagues [7]) don't find birds to be maniraptoran theropods vividly illustrates that they have not read my book [8]. Indeed, one must wonder if Smith et al. [5] had even read the actual article they are criticizing. The salient question, however, is at what level does the relationship of birds and maniraptorans exists?: are birds (as exemplified by early forms such as Archaeopteryx), derived maniraptoran theropod dinosaurs; or is the reverse true, that core maniraptorans (oviraptorosaurs, troodontids and dromaeosaurs) derived from volant early birds, the hypothesis supported by numerous authors $[4,7-9,13,18,74-76$, and others]. If so, then the current phylogeny is “topsy-turvy”[77].

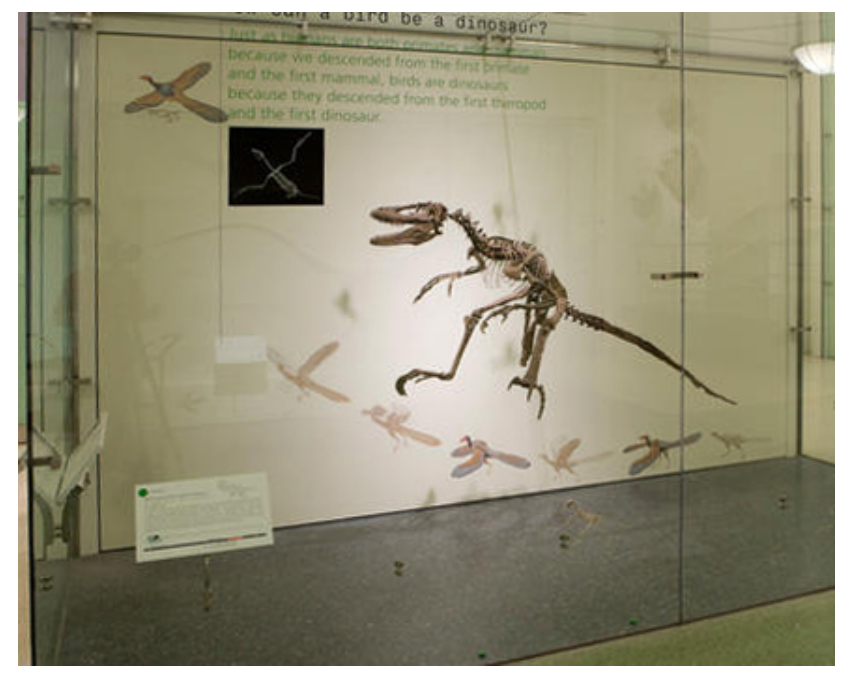

Fig. (4). Exhibit in the American Museum of Natural History showing the popular "ground up" ("gravity-resisted") theory for avian flight origins, largely advocated by Smith et al. [5]. The bird-like (3.4 m, $73 \mathrm{~kg})$ mid-Cretaceous maniraptoran Deinonychus is shown as part of a series of theropods leading to birds, and the exhibit notes: "The similarities between Deinonychus and early bird skeletons show that modern-day birds descended from small dinosaurs." In reality, it is much more probable that the Middle Cretaceous Deinonychus is derived within the maniraptoran lineage. This exhibit in no way supports the view expressed by Smith et al. [5] that the field has moved beyond the distinction of ground-up vs trees-down flight origins. Clearly, this exhibit is designed to show that the ground-up "gravity-resisted" model of flight origins is that favored today by the American Museum and the majority of paleontologists, to accommodate the cladogram. (reproduced with permission, American Museum of Natural History, courtesy Shilpa Patel; copyright Denis Finnin, AMNH).

The often-used statement that "birds are living dinosaurs" is meaningless, given the diversity of dinosaurs, and their similar morphology to their archosaurian antecedents. A striking example of the massive confusion resulting from this simple misleading phrase comes from a paper by Schweitzer et al. [78] on supposed, but unconvincing, protein sequences of the Late Cretaceous hadrosaur Brachylophosaurus. According to their cladogram theropod dinosaurs (e.g.Tyrannosaurus) come out closer to ornithischian dinosaurs (Brachylophosaurus) than to birds (Gallus and Struthio), a finding that would be totally at odds with the current orthodoxy of bird relationships. By their scheme a basal archosaurian avian origin would be equally or even more likely!

Likewise, in a beautiful study of embryology of the ascending process of the astragalus of dinosaur and bird ankles, designed to uncover homology [79], the authors fail to note that the ascending process of the astragalus is found in predinosaurian archosaurs [80 - 82], such as Lagerpeton and the lagosuchids (Marasuchus and allies), and therefore by cladistic logic would render the character of no use as a valid synapomorphy. The authors state that the ascending process originated in early dinosaurs along changes to upright posture and locomotion, but in fact it originated much earlier in mid-Triassic dinosaur precursors and is therefore of little interest in establishing a phylogenetic nexus of birds and dinosaurs. They also fail to fully establish homology of the condition in birds and dinosaurs, because the avian process forms as a neomorph from a disparate ossification center above the astragalus (also in Dilophosaurus), and in ratites becomes fused to the astragalus (pers. observation, ostrich embryos); whereas in all other modern birds it attaches to the calcaneum as a pretibial bone. The fact that in pre-dinosaurian Triassic dinosauromorphs the process 
"ascends" from the astragalus (ascending process), whereas in birds it is a long bone from a disparate ossification center that "descends" to either the astragalus or the calcaneum to fuse (descending process), renders this character of dubious utility in establishing a theropod-bird link. Avian and theropod ankles are "homologous" only in a very broad sense, and do not offer evidence of relationships.

Most disturbingly, Smith et al. [5] are quick to pull out the "creationist card,"comparing our arguments to methods of creationists. Yet, it is the current dinosaur-bird nexus of paleontology that has resulted in the creationists calling the field "The Disneyfication of Dinosaurs." And, one well-known creationist following a meeting on birds origins in 1999 , stated, "This is not science . . this is comic relief [83, 8]." The danger of any field that uses terms like "this debate has been settled" and "overwhelmingly convincing" to describe their findings, runs the risk of becoming a dogma, divorced from the normal scientific stringency required in most fields. Karl Popper noted presciently: "There is an even greater danger: a theory, even a scientific theory, may become an intellectual fashion, a substitute for religion, an entrenched ideology [84]." It is worthy of note that the current dinosaurian origin, with its corollaries, including dinosaur protofeathers, has been driven to its current position of prominence to no small extent by Nature editor Henry Gee, who became firmly committed to the doctrine back in 1996 and especially in 1998, when the cover of Nature featured a socalled feathered dinosaur Caudipteryx with true avian pennaceous flight feathers [85], thought by many paleontologists to have evolved in earth-bound dinosaurs in a non-flight context [86]. The problem, of course, is that these creatures, as noted, are most likely secondarily flightless birds with a flight propatagium [13] thus falsifying one of the most important publications on which the field was based. Birdlike characters for caudipterids and other bird-like taxa are given and analyzed in a number of papers [13, 87 - 90].

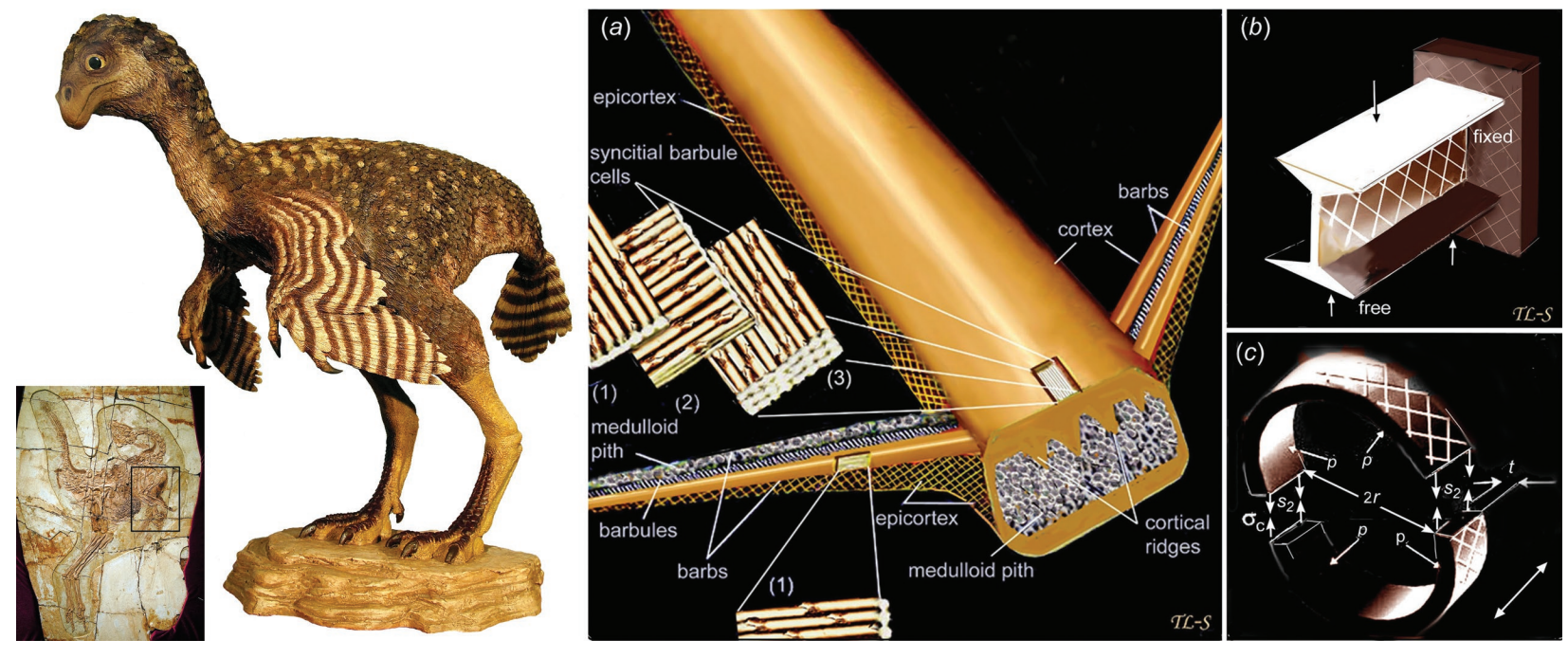

Fig. (5). Left, the basal oviraptorosaur Caudipteryx, a secondarily flightless bird, with inset from [13], lower left, showing an actual fossil exhibiting a propatagium, proving that it had volant ancestors. Note the similarity in skull structure with Scansoriopteryx, (Fig. 1). Right, illustration by T. Lingham-Soliar showing the biomechanical complexity of feather structure, designed for aerodynamic function. Microstructural fiber model of feather rachis and barbs and classic engineering analogues. a. An exploded view of three fiber divisions of the rachidial cortex and one of the barb cortex (both in dorsal and ventral walls). The cortex is identified by the thick syncitial barbules cells (6-8 $\mathrm{lm}$ in diameter). The lateral walls of the rachis and barbs, the epicortex, are characterized by a crossed-fiber structure and absence of syncitial barbules cells. One barb shows cortex removed to expose the medullary pith cells. b. Diagrammatic view of rachis and barb as an I-beam (here, a cantilever) in which most material is concentrated in the upper (tension) and lower (compression) surfaces to resist maximum stresses-with the "web" in the middle to resist shearing forces at $45 \pm^{\circ} \mathrm{c}$. Diagrammatic view of barb as a thin-walled pressure cylinder. Slice in latter shows circumferential stress (rc) is twice the longitudinal stress. Doubleheaded arrow long axis of cylinder (modified after Lingham-Soliar 2005b). From Lingham-Soliar T, Murugan N (2013) A New Helical Crossed-Fibre Structure of $\beta$-Keratin in Flight Feathers and Its Biomechanical Implications. PLoS ONE 2013; 8(6): e65849. doi:10.1371/journal.pone.0065849; Distribution under the Creative Commons License Deed, Attribution 2.5 Generic. Caudipteryx sculpture and inset copyright Stephen A. Czerkas, courtesy S. A. Czerkas.

The real question is: why would vertebrates evolve the most complex appendages, both embryologically and structurally, ever produced by the vertebrate integument, for any function other than flight? Fig. (5) shows a sculpture of Caudipteryx with an inset showing the propatagium, a leftover from its volant ancestors, and on the right is a diagram by Lingham-Soliar illustrating the biomechanical complexity of the pennaceous feather, a near perfect aerodynamic 
design. Such an elaborate construction would be gross overkill for anything other than aerodynamic function, and would be equivalent to insulating an ice truck with heat shields for the space shuttle! Feathers are light weight, have an exceptionally high strength to weight ratio with a ventral reinforcing furrow on the rachis, and graded flexibility and modular construction limit damage (when vanes are damaged they come back together like Velcro). Asymmetric vanes produce individual airfoil cross-sections with ventral camber, and together produce slotted wings with overall airfoil cross-sections, that produce high lift at low speeds. Flight remiges are designed to allow complete wing folding. Smooth aerodynamic contours of body contour feathers produce laminar flow over the body, thus reducing drag. Finally, they are, as an aside, insulatory (keeping heat in or out), and the fine structure of the feather vanes repel water. That such a structure would have evolved as an exaptation for any function other than flight is a major stretch of biological credulity.

Gee, a noted Tolkienist, who edits Mallorn, the Journal of the Tolkien Society, is also quick to state in Nature in 2006, "I am with the scientists of an earlier age [e.g. Richard Owen], who found that their motivation in advancing the cause of knowledge was to magnify the name of the Creator," and . . "the scientific process is not a parade of absolutes. Science is relative. Faith, however, is absolute [91]." Has Gee as a senior Nature editor taken this banner as a means of promoting the theropod origin of birds while ignoring any opposing views? Accusing Feduccia and colleagues of having any resemblance to the creationists, against this background, is tantamount to confessing that Smith et al. [5] never bothered to read "Riddle" [8] or the exegesis of it [4], which they attempt to criticize in their commentary.

\section{Gavin de Beer, Thomas Huxley and Percy Lowe}

Thomas Huxley features prominently in discussions of bird origins, but few appear to understand just what Huxley (and Percy Lowe) believed, and how their views differ from the writings of Gavin de Beer. Smith et al. [5] complain that, "Feduccia (2013) highlighted the theories of . . . de Beer . . . while ignoring others (e.g. Huxley 1867, Lowe 1935)," illustrating again that these authors have not read my book [8]. First, this is unequivocally and patently a false accusation. In my recent book 21 pages is devoted to Thomas Huxley (and Lowe) in a chapter entitled, "What did evolution's high priest say?" [8], and an additional 6 pages to Percy Lowe [8]; I refer the reader to this text for complete discussion. In brief, Huxley's "dinosaurian origin of birds" is difficult to wrap around, in that Huxley was struck by the similarity in hind limb structure between dinosaurs, including both the theropods Compsognathus and Megalosaurus, as well as the ornithopod Iguanodon (an ornithischian), and the chicken [8, 92]. However, the similarity is clearly due to the fact that chickens are highly adapted cursorial bipeds, with highly derived pelvic/femoral nexus. Yet, they differ significantly from these "dinosaurs" in the nature of the pelvic abutment (avian anti-trochanter vs. dinosaurian supraacetabular crest [93]), and in other features, such as having a pretibial bone $v s$. the dinosaurian ascending astragalar process. As I have noted many times [8], when birds such as ratites become secondarily terrestrial, they come to superficially resemble dinosaurs, and much confusion has resulted from this similitude. Aside from that problem, Huxley [94] viewed ratites as the key to the evolution of living birds: "The road from reptiles to birds is by way of Dinosauria to the Ratitae. "The bird 'phylum' was struthious, and wings grew out of rudimentary forelimbs," and Archaeopteryx for Huxley was a disconnected "intercalary bird" from that lineage, "It was a cousin, the royal line having already run from the 'bird-leg' dinosaurs to ostrich-like bird [95, 8, 49]." As I have noted before [96], Richard Owen, at odds with Huxley and Darwin largely over his theological beliefs, was able in one instance to dispense justice to both Darwin and Huxley: "science will accept the view of the Dodo as a degenerate Dove rather than as an advanced Dinothere [97]." At the same time, reflecting Huxley's view, "The differences which the wing-bones of the Dodo present when compared with their homologues in the Iguanodon is in the same degree adverse to the hypothesis of its evolution from any such reptiles, in the direction of ascent and improvement. The same course of argument applies to the impennate Awk, the Cassowary, Rhea, Ostrich, \& c, as to the wingless birds of the Mascarene, Polynesian, or Melanesian Islands (ibid)."

Huxley could not accept the idea that Archaeopteryx would be the ultimate avian ancestor because of its relatively late age at 150 million years; he thought the avian ancestor to be at least some 200 million years old, which would place their origin in the Triassic. Gigantic footprints discovered by Edward Hitchcock from the Triassic of Connecticut, predating Archaeopteryx by some 70 million years intrigued Huxley, and although the tracks would turn out to be those of bipedal theropods, Huxley's best guess was that they belonged to giant flightless birds resembling New Zealand moa that had been described earlier by Richard Owen. Clearly Huxley did not believe that the ultimate bird ancestor was Archaeopteryx, but flightless giants like today's ratites [8]. To turn the argument around, the evidence that "it is overwhelmingly convincing" ((exuberant expression of Smith et al. [5]) concerning the dinosaurian origin of birds, but with no acceptable morphological definition of theropod dinosaur)), it is also convincing that all extant flightless birds 
are derived from volant ancestors $[8,98]$ and not the reverse, as advocated by Thomas Huxley and Percy Lowe [8, 94, 99,100]. Percy Lowe followed Huxley in the "belief" that ratites were derived directly from dinosaurs (for Lowe, a common ancestor with small coelurosaurian dinosaurs), that is, ratites had evolved from creatures that never acquired flight. He further believed that Hesperornis was a "swimming ostrich," including it among the "aquatic or swimming palaeognaths": "as reptilian as it was possible to be without losing its claim to be avian . . . an aquatic palaeognath, just as the ostriches ... were cursorial palaeognathes . . there is little reason to think that either had volant ancestors [99]." He thus identified the theme of the current debate, that of polarity of the phylogeny, that flight originated in earth-bound dinosaurs that never went through a flight stage. He further believed that penguins derived from primarily terrestrial, nonflying ancestors, but this view was quickly dismantled by de Beer and G. G. Simpson [98, 101]. Huxley sought the origin of birds in the Permian or much earlier; indeed he envisioned the origin of mammals in the Silurian [95]. Despite the admonishment by Smith et al. [5] I am compelled to ally with Sir Gavin de Beer, who not only played a pivotal role in the development of the Modern Synthesis, but helped to create the field of Evo-devo, certainly not Thomas Huxley or Percy Lowe. Indeed, Smith et al. [5], in convoluted logic, falsely accuse me of suggesting a Permian origin of birds, but it was none other than their own historical mentor Thomas Huxley who did just that based on theropod footprints from Triassic sediments misidentified as avian, and thought by Huxley to be some ratite ancestor of modern birds, from a non-flight stage [95].

Yet, the modern paleontological view of bird evolution from ground up carries the indelible stamp of Huxley and Lowe. An axiom of the current orthodoxy is that early flying birds were derived from earth-bound dinosaurs that developed the sophisticated aerodynamic flight architecture in earth-bound dinosaurs, in a non-flight context. One sees this stamp in almost all the life reconstructions of basal birds, many of which exhibit sophisticated, derived flight architecture, but are almost always shown as terrestrial, predatory cursors. Most interestingly, current claims that Archaeopteryx is dinosaurian rather than of the avian clade, is marred by the fact that it clearly lacks any sign of either a dinosaurian supra-acetabular crest or an avian anti-trochanter, an indication of an earlier origin [93]. Hertel and Campbell point out that Archaeopteryx as well as Caudipteryx (also true for Scansoriopteryx and microraptors [13, 90]), lack a dinosaurian or avian dorsal bony abutment to the acetabulum, thus casting very serious doubt that any of these forms could be derived directly from theropods, all of which are defined by an invariably salient, completely open acetabulum and a dinosaurian supra-acetabular crest. Hertel and Campbell's research, largely ignored by paleontologists, brings up still another perplexing issue seldom discussed, the fact that there is currently no salient character definition for any of the taxa discussed, so that we can no longer define such simple terms as theropod, coelurosaur or carnosaur. Character definitions by the new cladistic analyses seem to be irrelevant and no longer of interest, just the result of the computer-generated cladogram. Examining the term Dinosauria, one finds that among the most salient characters are the pelvis and hind limb structure, exhibiting a completely open acetabulum associated with a complete suite of postural and gait changes, lending to an upright posture and an obligately bipedal gait, with limbs held in a parasagittal plane. Other associated features include a supra-acetabular crest and the femur head bent proximally, at right angles, with the femur in the parasaggital plane; thus forces are directed to the dorsal aspect of the cup of the acetabulum, and a bony wall, the supra-acetabular crest resists excessive medially directed forces. This arrangement is combined with dramatically reduced fore limbs to about half the length of the hind limbs. There is also a massive balancing tail. How then, could forms such as the scansoriopterids, or even microraptors possibly be considered coelurosaurian theropods?

It would seem extraordinarily unlikely that such a combined suite of complex characters would be lost in more advanced putative theropods, such as the microraptors, Anchiornis and allies, Archaeopteryx, Caudipteryx, and scansoriopterids (see [13, 18] for avian and non-theropod characters). Too, many of the four-winged glider maniraptorans have a well-developed avian flight hand, some of which are clearly more advanced than that of Archaeopteryx. What is missing from the criticism of Smith et al. [5] is that I, and many others, believe that the evidence is increasingly supportive of the view that at least the core maniraptorans (oviraptorosaurs, dromaeosaurs and troodontids, the Pennaraptora of Foth, Tischlinger and Rauhut, minus oviraptorosaurs [102]) are avian derivatives, from the early avian radiation, and are derived, not basal to the avian lineage. This view is also supported by the recent new cladistic analyses [7, 25, see Fig (6)]. For Xu et al. [25] the old term "deinonychosaurs (troodontids and dromaeosaurs) are within the avian domain, but oviraptorosaurs are not considered. In still another scheme Agnolin and Novas [103] remove microraptors from the Dromaeosauria (appears unjustified), and Deinonychosauria is not used. They do, however, place Oviraptorosauria and Scansoriopterygidae in the same clade, based on similarity of skull structure, but continue to follow the "Birds are Maniraptoran Theropod" hypothesis. It is apparent from these varied analyses that we all agree that birds are maniraptorans, and that the core maniraptorans are derivative, rather than ancestral to birds, with 
scansoriopterids at the base. Could the scansoriopterids be early volant offshoots of the lineage of oviraptorosaurs that also produced a flightless radiation? While much detail needs to be worked out, given the rancor expressed by Smith et al. [5] over minority views, it is amazing yet encouraging to see the degree of convergence of views.

Paul has also supported the view that the current paleontological phylogeny is topsy-turvy, with microraptors and allies, including Caudipteryx, being secondarily derived from flying ancestors [74]. Paul shows that forms such as the Early Cretaceous Sinornithosaurus exhibits not only an avian flight hand but a flight hand more advanced than that of the urvogel Archaeopteryx. Forms from Deinonychus to Sinornithosaurus have a highly developed flight hand, similar in structure to modern flightless birds that were all derived from volant forms. Indeed, Sinornithosaurus has a more advanced flight hand than does Archaeopteryx, with a nicely bowed outer metacarpal to support flight remiges, and amazingly, a well-developed posterolateral flange (broader distally than proximally, as in modern volant birds), which on the central finger bones greatly improves anchoring of large feathers, whose bases are set on the dorsal surface of the flange. This flange is prima facie evidence of flight function, and when present in flightless forms must be considered evidence of evolution from once volant ancestors. As Paul put it, "The feather-anchoring finger flange by itself directly challenges standard cladistic analyses of dinosaur-bird relationships [74]." Are these fully feathered and winged Chinese "feathered dinosaurs" part of the early avian radiation, at varied stages of gliding, flight and flightlessness, masquerading as dinosaurs. Are these the hidden birds of China?

\section{Censorship of Opposing Views}

It is often the case that contrary views lead to vigorous testing and re-testing of hypotheses, either lending stronger support for existing theories or falsification. It is therefore regrettable that censorship is common, and comes in three primary forms: summarily rejecting manuscripts in opposition to the current orthodoxy, either by editors or referees; refusal to cite published articles supporting opposing views; and lastly, writing scathing book reviews with ad hominem attacks. I have previously pointed out the problem of lack of citation [4, 96], but less well-known is continued attempts to silence opposition by writing caustic and vitriolic reviews of books that have substantial merit.

In a cynical and disingenuous review of Riddle of the Feathered Dragons [104], Chiappe states that no modern study has hypothesized a direct ancestor-descendant relationship between compsognathid theropods and Archaeopteryx; to put it another way, he knows of no one who considers coelurosaurs the ancestors of birds. This is a circumvention of the problem, since most workers consider compsognathids revelent to bird origins, and Ostrom's own theory often made the case for a dinosaurian origin of birds from small coelurosaurs by stating that the Eichstätt specimen of Archaeopteryx was first misidentified as the small coelurosaurian Compsognathus! For Ostrom this error was proof of relatedness; although another specimen of Archaeopteryx was misidentified as a pterosaur. By today's cladograms (Fig. 6) coelurosaurs are simply assumed a priori to be basal to the avian phylogeny, close to birds, without any morphological definitions. Most interestingly John Ostrom considered Deinonychus to be a coelurosaur, and today compsognathids are within the Coelurosauria, but clearly forms like Sinosauropteryx are not anywhere close to bird orgins. Finally, contrary to Chiappe's rant, Zhou and Hou state "Sinosauropteryx a small coelurosaur closely allied with Compsognathus was initially described as a primitive bird linking dinosaurs and later birds ,.. [105]."

Chiappe and Padian do not believe in any validity to Dollo's Law, despite abundant evidence to the contrary [8, 52, 106, 120 - 128]. Chiappe [104] states:“ . . resting on Dollo's law of irreversibility, Feduccia questions whether it is "biologically possible to reevolve the already greatly foreshortened forelimbs" of a number of nonavian theropods into the elongate wings of birds. He details well-known exceptions to Dollo's law, but ends by proclaiming, "Certainly 'compsognathid' arms could not reelongate into Archaeopteryx wings." This is typical of the mischaracterizations of opposing views employed. In reality however the exceptions to Dollo's law (rule) are few, many may well be errors in cladistic analyses, and other studies suggest that, "Our findings do not necessarily overturn the conclusions of phylogenetic studies claiming reversals, but we demonstrate devastating flaws in the methods that are the foundation of all such studies," and "More powerful tests of irreversibility require data beyond phylogenies and character states of extant taxa [106]." Regardless, the transition would have to begin with an early theropod to dromaeosaurs, and that in itself would involve a substantial increase in arm and hand length. And, if miniaturization through heterochrony were involved the already foreshortened forelimbs would be attenuated even more, with dramatic disto-proximal shortening. Certainly making a transition from a stubby forelimb approximately $50 \%$ the length of the hindlimb, with a tiny hand, to the elongate forelimbs of early birds, slightly longer than the hindlimbs, with elongate hands would be an overwhelmingly difficult transmutation (Fig. 7). 


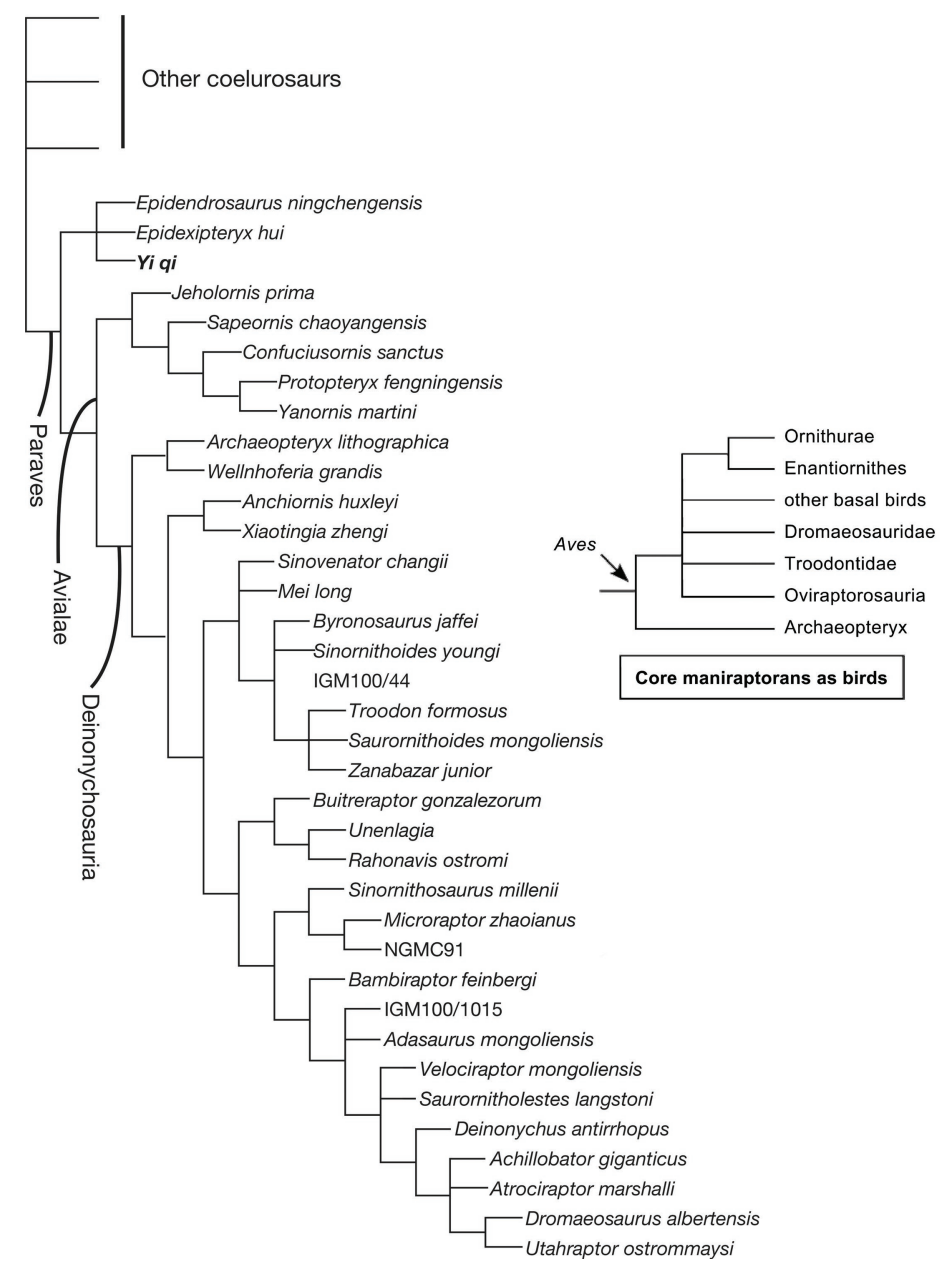

Fig. (6). The "Birds are Maniraptoran Theropods" hypothesis is the dominant view today, but the controversy arises as to whether the "core maniraptorans" (variously defined, but normally including oviraptorosaurs, troodontids and dromaeosaurs) are basal or derived. That they are derivatives of the early avian radiation is the view favored here, and can be seen in many recent cladograms, as shown here from a very recent simplified "coelurosaurian" phylogeny showing the position of the newly discovered Jurassic scansoriopterid $Y i$ [25]. Right, simplified cladogram by James and Pourtless [7], showing core maniraptorans as birds, the view favored here. Note that the central core of the phylogeny does not differ in basic concept from that promoted by myself and many others, showing core maniraptorans within the avian domain, without getting into the cladistic lexical morass. Many would disagree with some of the internal arrangements; for example, Microraptor and Sinornithosaurus are often recovered as basal dromaeosaurs; and oviraptorosaurs are excluded, which I consider derived, secondarily flightless birds, with the basal form Protarchaeopteryx as a volant member. By this view, promoted by Feduccia [4, 8, 9, 77], James and Pourtless [7], Czerkas [13, 18, 24] and many others, core maniraptorans are descendants, rather than ancestors of basal birds; thus the more derived forms are descendant and not ancestral (Feduccia's Topsy-turvy bird phylogeny $[9,77]$ ). By this view all the problems with bird origins, both from the standpoint of skeletal characters, re-elongating and refashioning already foreshortened forelimbs, digital homology, and ground-up flight origins disappear.

The Origin and Evolution of Birds, Feduccia's award-winning book of 1996, which many admired for its breadth of biological perspective [107] was also attacked by Norell and Chiappe; as palaeontologist Dodson notes, "authors committed to an exclusively cladistic perspective have dealth with it both swiftly and harshly [107]." The book won high praise from such luminaries as Ernst Mayr, but Norell and Chiappe wrote a blistering review in Nature entitled "Flight from reason" [108], about which paleontologist Dodson [ibid] commented: "Such a sulfurous heading poisons the well of scientific discourse and seems unworthy of an otherwise respected and responsible journal. Another review by Padian, primary supporter of the failed theory of ground-up flight origins in birds and pterosaurs, in a similar vein blasts Feduccia as follows: "Science depends not on authoritarianism, not on hegemony of single fields, and not on majority votes, but on method. Progress is made not only as more evidence accumulates, but also as methods of analyzing evidence are developed, tested, and standardized (emphasis mine). The difficulty of the present debate is that the methods used by the rest of the community are not used by a few who still object not only to those methods but to 
their results" [109]. Such methods are "now generally preferred by the systematic community, including reviewers for the systematic division of the National Science Foundation" (Padian, ibid.). Dodson noted of Padian's comment, "Such statements could be interpreted as promoting hegemony of ideas for systematic analysis and using the ultimate threat in science, the withholding of funding, for dissenters [106]."
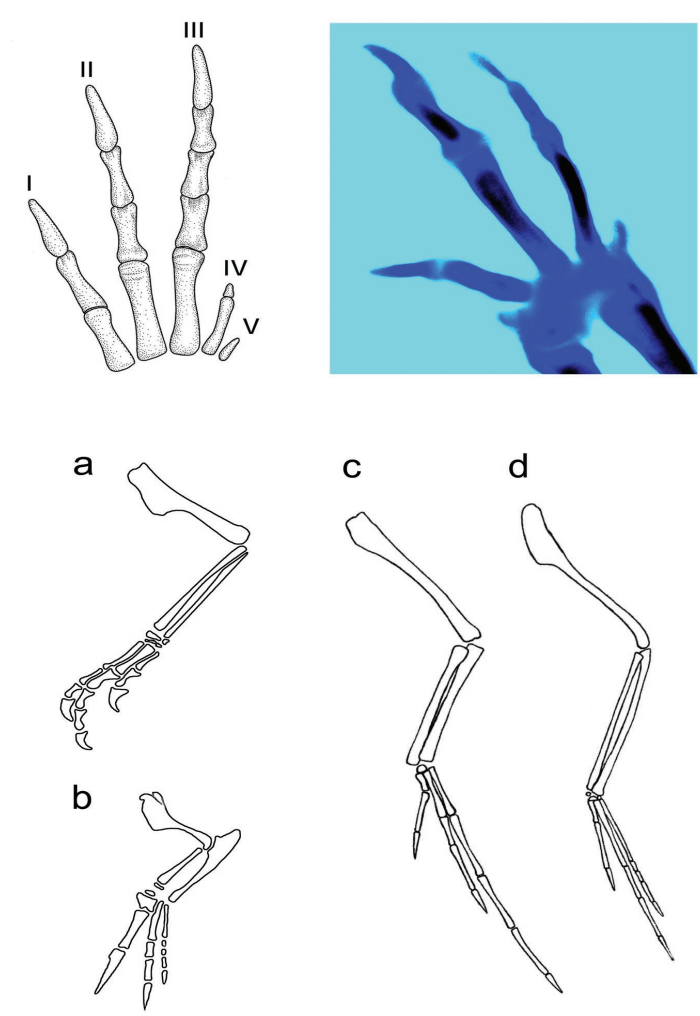

Fig. (7). Problematic transitions. Coelurosaurs are included in many cladograms, based on the a priori assumption they are closest to birds, but an evolutionary transition from so-called coelurosaurs to birds is no simple feat, morphologically or embryologically. Above, right, the hand of an ostrich embryo at day 14-15 showing well-developed condensations for digits II-III-IV, with greatly reduced, vestigial condensations for digits I and V. This is the typical amniote pattern of symmetrical reduction. Yet, the hand of the Triassic basal saurischian Herrerasaurus, upper left, (possible theropod) as with other Triassic forms, exhibits the typical theropod pattern of asymmetrical reduction, producing a hand with digits I-II-III, a grasping raking hand. In Herrerasaurus the greatly reduced and vestigial digits IV and V are clearly present. In attempts to accommodate the cladogram those supporting the current orthodoxy propose a homeotic frameshift, but this almost takes on the form of a "Deus ex Machina" and would have occurred with no obvious selective advantage, somewhere between "Allosaurus and birds." Too, why would there have been a frameshift, if "birds are dinosaurs" and would have already possessed the theropod hand at their origin? Below, forelimbs of (a) Triassic herrerasaurid, and (b) compsognatid coelurosaur Sinosauropteryx, compared to, right, Scansoriopteryx (c) and Archaeopteryx (d). Such a transition would represent an abrogation of Dollo's rule, involving the re-elongation of already fore-shortened forelimbs, to half the length of the hindlimbs, with totally different proportions and stubby hands. Other problematic areas include the pelvis where many of the basal avian taxa, such as the scansoriopterids and anchiornithids have a partially closed acetabulum and lack a supra-acetabular crest. Even Caudipteryx and Archaeopteryx do not possess a supra-acetabular crest, and thus birds would have to first lose the dinosaurian pelvic characters associated with obligately bipedal posture and then re-evolve this complex feature. The pelvis of scansoriopterids appears like that of basal archosaurs, and the pubis is non-dinosaurian. Left, from Feduccia, adapted from Sereno PC. J Vert Paleo; 1990; 180: 21-51; upper right, modified from Feduccia [55]. Lower images: Left, a herrerasaurid (after Sanjuansaurus, adapted from Alcobar OA. Zoo Keys 63:55-81; lower, Sinosauropteryx (adapted from various sources). Right, wings of Scansoriopteryx and Archaeopteryx, adapted from S. A. Czerkas [24].

Despite Chiappe's (and Norell's) blistering reviews of two of Feduccia's books on bird origins, eminent paleontologist Keith Thomson, former Director of both the Peabody Museum of Natural History at Yale and the Oxford Museum of Natural History, could write a blurb for "Riddle": "a marvelous essay on method and interpretation in paleontology. And it wonderfully captures the fluid state of our knowledge and the tenuous state of our interpretations [8: cover blurb]." 
Finally, Chiappe and Padian had been proclaiming that no one in opposition to their views had provided a testable alternative using cladistic analyses. Then, in 2009, when Frances James and John Pourtless published their Ornithological Monograph no. 66 [7] producing new cladistic analyses with results contrary to current orthodoxy, no one from the field of paleontology, including notably Chiappe, Padian or Norell would even deign to cite the paper ((as Feduccia [96] has noted, an unscholarly, but effective form of censorship)). Yet, Smith et al. [5] could, at the time, say that, yes, the monograph has been cited (twelve times!). But upon examination at the time of Google Scholar, one finds that the only paleontologist among their group to do so was Makovicky in a scorching criticism [110]. Regardless, the James and Pourtless monograph remains among the most important, but totally ignored, detailed accounts on the subject ever written!

\section{Massive Exaptations are Non-Darwinian}

The most troubling aspect of the current orthodoxy of bird origins is that the total suite of ultra-sophisticated aerodynamic flight architecture, including but not limited to, pennaceous flight remiges, highly specialized avian flight hand, neurological brain structures and inner ear, all evolved in earthbound dinosaurs in a non-flight context, a proposal that is practically non-Darwinian [4, 9, 96]. As James and Pourtless [7] note: "If the most birdlike maniraptoran clades belong within Aves, problematic exaptational explanations, including those for the origin of flight, are unnecessary."

The model proposed by me and others overcomes this major deficiency, taking us back to the orthodoxy for most of the $20^{\text {th }}$ century, with birds being viewed as cousins rather than direct descendants of already highly specialized terrestrial theropods. By this view, birds are descended from small tree-living archosaurs or dinosauromorphs that developed flight architecture in an aerodynamic context, not for insulation or display. Flight originated by the facile arboreal model, taking advantage of small size and high places, the cheap energy provided by gravity. Thus, the arboreal model is "gravity-assisted," the cursorial model is "gravity-resisted." Our phylogeny has changed based on new discoveries from China, and will continue to change as new evidence emerges, but the new models are not revolutionary but fresh applications of de Beerian biological thought [9, 98]. De Beer's major axiom still holds as before: if it has avian flight feathers and avian flight wings, it's a bird.

I have had the opportunity to study many of the Chinese Jehol specimens numerous times, both in Beijing and in the United States (Washington, DC, Florida, California, and especially the University of Kansas), and never ceased to be amazed at the splendid preservation. Smith et al. [5] assert that my claim that these fully feathered Chinese fossils such as Microraptor, Caudipteryx, etc. are likely hidden birds has not been substantiated; yet there are myriad highly derived aerodynamic avian characters that have been noted [7, 8, 13, 18, 74, 76, 87 - 90]. It is clear that among the array of newly discovered Chinese fossils there are perfectly good theropods such as Sinosauropteryx, but many of the fossils described as birdlike may indeed be early birds, such as microraptors (including Sinornithosaurus), Anchiornis and allies, and particularly Caudipteryx, the former with an avian flight hand more advanced than that of Archaeopteryx, and has been classified many times as a secondarily flightless bird [13]. All these forms have highly developed avian wings, with the precise avian attachment of flight remiges, and most exhibit more advanced bird characters than the urvogel Archaeopteryx.

\section{Feathers, Feathers, Everywhere.}

Finally, as noted, comments on the discovery of putative, but unproven, protofeathers [111, 112] and the reports of color of dinosaurs [113], now refuted [114, 115], will be covered by T. Lingham-Soliar in a separate paper. In brief, this field has attempted to advance far beyond the scientific evidence and, despite special pleas by Norell and Xu [112], Clarke [116] and others, there is yet to be any convincing evidence for the existence of protofeathers in any known dinosaur, ornithischian [117] or saurischian [118]. Too, the evidence for the famous colored dinosaur Sinosauropteryx is deficient by any scientific yardstick [114], and reports of feather color [113, 119 - 122], and even identification of protofeathers based on melanosomes has now been seriously questioned [123 - 125]. There are clearly different reports of protofeathers that conflate dermal skin fibers from true theropods (e.g. Sinosauropteryx.) with variously fossilized true feather structures from taxa of the Chinese Jurassic and Cretaceous that also exhibit true avian pennaceous feathers, and show evidence of avian status, which I believe are of avian affinity. The so-called dinosaur protofeathers are generally collagen fibers or even a variety of structures, and the fibers of Sinosauropteryx are clearly beneath the skin [8]. Then there are forms such as Microraptor and other maniraptorans with true pennaceous feathers, which have also been reported to possess protofeathers. Many of these reports may be from pennaceous feathers that have undergone maceration or been altered by taphonomic diagenic processes that produce simpler structures that might appear to 
resemble hypothetical protofeathers. But, to date there is no demonstrable scientific evidence for the existence of protofeathers in any fossil or living animal.

On the question of identifying feather color based on the presence of putative melanosomes, Moyer et al. [123] showed extreme difficulty in distinguishing remnant melanosomes and pervasive bacteria, which are virtually indistinguishable. As Lindgren et al. [124] showed, "differentiation of melanosomes from microorganisms is necessary because they overlap in size, shape and distribution. Moreover, microbes are always associated with decaying carcasses, and are known to fossilize as both organic and inorganic traces." Lindgren et al. [124] summarize, new and innovative "approaches will ultimately facilitate more rigorous interpretations and reduce the risk of spectacular yet insufficiently supported claims propagating in the literature." Finally, even if melanosomes can be identified, the overall technique is totally deficient. Manning et al. [125], using highly sophisticated synchrotron based techniques to assess fossil feather color, noted that, "Studies on the elucidation of colour in fossil feathers have suggested that the presence of melanosomes within fossil feathers may be used to tentatively reconstruct feather colours by tracking variations in melanosome shape. Rod shapes were interpreted as eumelanosomes (dark black/brown) and spheroidal shapes as pheomelanosomes (reddish-brown). This structural approach has some shortcomings, primarily that there is known diversity in melanin granule morphology among different species and melanosome preservation may not be uniform. Therefore, serious questions may be raised about colour interpretation based solely on fossilised melanosome morphology and distribution. Additionally, these studies did not account for other known contributors to colour in feathers, such as the possible presence of other pigments (e.g. carotenoids) or other physical structures." Continuing [ibid:1029], they point out that, " in order to resolve feather colour in fossils, a combination of both structural and chemical analyses is necessary. Structural electron microscope based approaches to diagnosing colour typically rely upon data collected from less than $1 \%$ of a fossil's total surface area (often compromising sample integrity) whereas the non-destructive synchrotron based techniques image $100 \%$ of a sample and the surrounding matrix. Structural approaches cannot spatially resolve information on the intensity and distribution of either the chemical inventory or the pigment density (patternation)." Thus, recent studies on fossil melanosomes must be abandoned.

Distressingly, the entire "revolution" that was driving the last two decades of sensationally frenzied excitement in the world of paleontology and ornithology was initially based on two faulty discoveries: a) the supposed discovery of protofeathers in Sinosauropteryx [111], and b) the discovery of the feathered dinosaur Caudipteryx [85], a secondarily flightless bird; both published in Nature under paleontology editor Henry Gee, who proclaimed "the debate is over" [1] following the discovery of Caudipteryx!

\section{CONCLUSION}

Much of science has advanced by conscientious individuals plodding along, doggedly pursuing science in their laboratories, with little attention to methodology; and recently Diamond and Robinson [126] have been so bold as to suggest that, "Natural experiments are not an inferior, second-class science." Yet, the study of systematics has become stiflingly restrictive in its insistence on an inflexible, rigid methodology. Dodson [107] noted perspicaciously that the new methodology "excludes data from stratigraphy, embryology, ecology, and biogeography that could otherwise be employed to bring maximum evolutionary coherence to biological data. Darwin would have convinced no one if he had been so restrictive in his theory of evolution." There are many well enacted cladistics analyses that have made significant contributions to the field, but unfounded overconfidence in methodology, what Smith et al. [5] term "modern systematics" has resulted in innumerable errors, as noted, generally the result of attempts to accommodate the cladogram in everything from biomechanics, behavior and fossil reconstructions, to identification of fossil structures . The "cladistics revolution" has been justifiably criticized for blending science with ideology, and several generations of systematists "were often caught up in a religious-like fervor, trumpeting the virtues of cladism and crusading to convert nonbelievers and agnostics to their scientific faith [127]."

Persistent problems plague the field, including but not limited to: use of key characters to exclude taxa as outgroups in cladistics analyses; poorly conceived analyses of genome size to ally birds and dinosaurs; failed attempts by many to show the modern bird orders originated between 100 to $120 \mathrm{Ma}$; misidentifications of a putative Cretaceous parrot with an unidentifiable bone, and a putative but totally unsubstantiated modern duck in the Late Cretaceous (both published in Nature), apparently in search of the discovery of non-existent modern bird families prior to the K-Pg boundary. Others include explanations of distributions of flightless ratites through vicariance biogeography; identification of fibers on dinosaurs as protofeathers, but providing no biological or structural evidence; use of scrappy fossil material to explain the early evolution of avian flight; ground-up, "gravity-resisted" flight origins based on birds being derived from earth- 
bound dinosaurs, and use of ontogeny of highly derived hill-climbing galliforms to decipher flight origins. There has also been extensive reliance on explanations of character origins as exaptations, with the evolution of the most highly sophisticated aerodynamic structures in vertebrates (avian flight remiges) having evolved in a context other than aerodynamic, in earth-bound dinosaurs. The later proposal is practically non-Darwinian.

Historically, the Ostrom-based dinosaurian origin of birds, dating back to the early 1970s was largely based on the following tenets, which still enjoy a majority view today among paleontologists:

a. Dinosaurs developed endothermy, based on upright, bipedal posture (following the model for endothermy developed in therapsids with upright posture leading to mammals), and primitive insulatory feathers evolved in endothermic dinosaurs (hence protofeathers in Sinosauropteryx).

b. Protoavians were cursorial animals, similar to Deinonychus and Velociraptor, that used wings as predatory insect traps, leading to the development of flight feathers as an exaptation, in a non-flight context.

c. Archaeopteryx was largely terrestrial and earth-bound, learning to fly from the ground up, and supported two theories: the dinosaurian origin of birds and endothermy in dinosaurs.

Evidence negates all these postulates and I see no reasonable evidence for endothermy in dinosaurs or Archaeopteryx [8]. In the very monotonously warm Cretaceous Period dinosaurs would have been facultative homoiotherms, and would thus have enjoyed the high levels of activity without having to consume excessive food. Large reptiles are typical of tropical zones for obvious reasons.

Open wings as predatory insect traps is functionally unsound. And, Archaeopteryx exhibits highly recurved pedal and manual claws with extreme lateral compression, as in trunk-climbing birds and mammals; it was a trunk-climbing, volant bird. Finally, ground-up "gravity-resisted" flight is biomechanically improbable and there is no valid current model supporting it. Ostrom's views were not based on cladistics, but were later codified in a cladistics framework. Regrettably, today much of the speculative science, including biomechanics involves accommodating the cladogram whatever the result.

Despite the hotly debated issues on bird origins today there may be signs of consilience, as many of the more recent phylogenies appear to be converging towards some common themes. Xu and colleagues [25] in their excellent 2015 description of the Jurassic small, volant basal scansoriopterid $Y i$ qi ("strange wing"), close to base of avian origins, identify the digits as II-III-IV for $Y i$ and other maniraptorans, "following the position-based numbering" which conforms to the embryological digital condensations, with digits I and V reduced in avian embryos and eventually disappearing. Digit I has been identified in ostrich embryos but disappears after day 14-15 with a vestigial condensation for digit V persisting somewhat longer [55]. I have noted before that it is likely that maniraptorans and birds represent a clade characterized by a II-III-IV hand [8].

The real question remains: "whence birds?" The morphological transformation going from basal theropods such as Herrerasaurus to some basal avian similar to the scansoriopterids or archaeopterygids is an incredible transmutation, one that defies Dollo's law. It would involve transforming already foreshortened forelimbs, half the length of the hindlimbs to wings, as long, or slightly longer than the hindlimbs (Fig. 7). Then, too, scansoriopterids simply do not exhibit skeletal characters of theropods, and it has been argued that they are not at that level [8]. Aside from the forelimbs, the skull and especially the teeth are strictly non-theropodan, as well as the femur and pelvis, which has neither an open acetabulum nor a supra-acetabular shelf, and the ilium and pubis likewise cannot be considered theropodan. Many of these same comments apply to microraptors, which are incorrectly reconstructed, like the scansoriopterids (Fig. 1) as earth-bound mini-theropods. In tetrapteryx gliders, the highly elongate hind-limb remiges would be a major hindrance to terrestrial locomotion. We still have much to learn and it is imperative that all parties maintain an open mind, willing to modify views with new discoveries. No taxonomic definitional sleight of hand will add anything to the overall phylogenetic concepts.

Those who question the current model don't pretend to have all the answers on bird and feather origins, but one thing is certain: the current phylogeny is replete with problems and is likely topsy-turvy, and the accepted orthodoxy on bird origins is incapable of explaining the observable facts. Too, perhaps the most dramatic discovery of the past several decades, the supposed existence of protofeathers in dinosaurs, is totally deficient, lacking the normal, required scientific rigor necessary for acceptance of what would be an extraordinary discovery. As for the Commentary by Smith et al. [5], Author Schopenhauer, $19^{\text {th }}$ century German philosopher, noted that all new ideas pass through three distinctive stages: first, there is ridicule; second, there is outrage; and third, the idea is accepted as self-evident [128]. We are regrettably in 
the middle of stage 2, outrage, but hopefully headed to stage 3, a stage at which the arboreal theory for flight origins has already arrived. Regardless of the ultimate outcome, we urge that all birds be allowed to sing. Freedom of expression in this debate can cause no harm and may in fact lead to new avenues not yet investigated. "Healthy skepticism is the most powerful tool of science and should be cherished as a welcome anodyne to the complacency of certitude [129]."

\section{CONFLICT OF INTEREST}

The author confirms that this article content has no conflict of interest.

\section{ACKNOWLEDGEMENTS}

I thank F. James and T. Lingham-Soliar for discussion and comments on the manuscript. S. Chatterjee, S. J. Czerkas and the late S. A. Czerkas, F. James and T. Lingham-Soliar kindly provided figures, which were composed by Susan Whitfield. The specimen of Caudipteryx (Fig. 5) [13] was on loan from the Institute of Geology, Chinese Academy of Geological Sciences and has been returned. I thank Ji Qiang for his kind help.

\section{REFERENCES}

[1] Gee H. Birds are dinosaurs: the debate is over. Nature Science Update 1998. [Online] www.nature.com/nsu/980702-8.html. [http://dx.doi.org/10.1038/news980702-8]

[2] Prum RO. Why ornithologists should care about the theropod origin of birds. Auk 2002; 119(1): 1-17. [http://dx.doi.org/10.1642/0004-8038(2002)119[0001:WOSCAT]2.0.CO;2]

[3] Prum RO. Are current critiques of the theropod origin of birds science? Rebuttal to a. Feduccia (2002). Auk 2003; 120(2): 550-61. [http://dx.doi.org/10.1642/0004-8038(2003)120[0550:ACCOTT]2.0.CO;2]

[4] Feduccia A. Bird origins anew. Auk 2013; 130(1): 1-12. [http://dx.doi.org/10.1525/auk.2013.130.1.1]

[5] Smith NA, Chiappe M, Clarke JA, et al. Rhetoric vs. Reality: a commentary on "Bird Origins Anew" by A. Feduccia, Auk (2013, 130:1-12). Auk 2015; 132(2): 467-80. [http://dx.doi.org/10.1642/AUK-14-203.1]

[6] Sagan C. Cosmos. New York: Random House 1980.

[7] James FC, Pourtless JA. cladistic and the origin of birds: A review and two new analyses. Ornithol Monogr 2009; 66: 1-78. [http://dx.doi.org/10.1525/om.2009.66.1.1]

[8] Feduccia A. Riddle of the feathered dragons: hidden birds of China. New Haven, CT: Yale University Press 2012.

[9] Feduccia A. Is it a bird? Is it a dinosaur? The Big Idea: New Scientist 2012. [http://dx.doi.org/10.1016/S0262-4079(12)61084-7]

[10] Popper K. Conjectures and Refutations. London, UK 1963.

[11] Irwin DM. Dead branches on the tree of life. Review of: Gee, H 1999 In Search of Deep Time: Beyond the Fossil Record to a New History of Life 2000; 403: 480-1. [http://dx.doi.org/10.1038/35000635]

[12] Feduccia A. Avian extinction at the end of the Cretaceous: Assessing the magnitude and subsequent explosive radiation. Cretac Res 2014; 50: $1-15$.

[http://dx.doi.org/10.1016/j.cretres.2014.03.009]

[13] Feduccia A, Czerkas SA. Testing the neoflightless hypothesis: Propatagium reveals flying ancestry of oviraptorosaurs. J Ornithol 2015; 156(4): 1067-74. [http://dx.doi.org/10.1007/s10336-015-1190-9]

[14] Jarvis ED, Mirarab S, Aberer AJ, et al. Whole-genome analyses resolve early branches in the tree of life of modern birds. Science 2014; 346(6215): 1320-31. [http://dx.doi.org/10.1126/science.1253451] [PMID: 25504713]

[15] Wright NA, Gregory TR, Witt CC. Metabolic ‘engines' of flight drive genome reduction in birds. Proc Royal Soc, part B 2014 ; 281 [http://dx.doi.org/doi.org/10.1098/rspb.2013.2780]

[16] Evangelista D, Cam S, Huynh T, et al. Shifts in stability and control effectiveness during evolution of Paraves support aerial maneuvering hypotheses for flight origins. PeerJ 2014; 2: e632.

[http://dx.doi.org/10.7717/peerj.632] [PMID: 25337460]

[17] Lingham-Soliar T. The evolution of the feather: Sinosauropteryx, a colourful tail. J Ornithol 2011; 152: 567-77. [http://dx.doi.org/10.1007/s10336-010-0620-y]

[18] Czerkas SA, Feduccia A. Jurassic archosaur is a non-dinosaurian bird. J Ornithol 2014; 155(4): 841-51. [http://dx.doi.org/10.1007/s10336-014-1098-9] 
[19] Zhang F, Zhou Z, Xu X, Wang X. A juvenile coelurosaurian theropod from China indicates arboreal habits. Naturwissenschaften 2002; 89(9): 394-8. [http://dx.doi.org/10.1007/s00114-002-0353-8] [PMID: 12435090]

[20] Zhang F, Zhou Z, Xu X, Wang X, Sullivan C. A bizarre Jurassic maniraptoran from China with elongate ribbon-like feathers. Nature 2008; 455(7216): 1105-8. [http://dx.doi.org/10.1038/nature07447] [PMID: 18948955]

[21] Xu X, Ma QY, Hu DY. Pre-Archaeopteryx coelurosaurian dinosaurs and their implications for understanding avian origins. Chin Sci Bull 2010; 55(35): 3971-7.

[http://dx.doi.org/10.1007/s11434-010-4150-z]

[22] Marquez AP. A juvenile Edmontosaurus from the late Maastrichtian (Cretaceous) of North America: Implications for ontogeny and phylogenetic inference in saurolophine dinosaurs. Cretac Res 2014; 50: 282-303. [http://dx.doi.org/10.1016/j.cretres.2014.05.003]

[23] Picasso MB. Postnatal ontogeny of the locomotor skeleton of a cursorial bird: Greater Rhea. J Zool (Lond) 2011; 286(4): 303-11. [http://dx.doi.org/10.1111/j.1469-7998.2011.00880.x]

[24] Czerkas SJ, Ed. Feathered dinosaurs and the origin of flight. Blanding, Utah: The Dinosaur Museum 2002.

[25] Xu X, Zheng X, Sullivan C, et al. A bizarre Jurassic maniraptoran theropod with preserved evidence of membranous wings. Nature 2015; 521(7550): 70-3.

[http://dx.doi.org/10.1038/nature14423] [PMID: 25924069]

[26] Padian K. Palaeontology: Dinosaur up in the air. Nature 2015; 521(7550): 40-1. [News and Views]. [http://dx.doi.org/10.1038/nature14392] [PMID: 25924067]

[27] Hu D, Hou L, Zhang L, Xu X. A pre-Archaeopteryx troodontid theropod from China with long feathers on the metatarsus. Nature 2009; 461(7264): 640-3.

[http://dx.doi.org/10.1038/nature08322] [PMID: 19794491]

[28] Chatterjee S, Templin J. Palaeoecology, aerodynamics, and the origin of avian flight. In: 2015.

[29] Chatterjee S. The rise of birds.

[30] Turner AH, Pol D, Clarke JA, Erickson GM, Norell MA. A basal dromaeosaurid and size evolution preceding avian flight. Science 2007; 317(5843): 1378-81. [Supporting online material: www.sciencemag.org/content/supp1/2007/09/06/317.5843.1378.D C1/Turner.SOM.pdf] [http://dx.doi.org/10.1126/science.1144066] [PMID: 17823350]

[31] Lee MS, Cau A, Naish D, Dyke GJ. Dinosaur evolution. Sustained miniaturization and anatomical innovation in the dinosaurian ancestors of birds. Science 2014; 345(6196): 562-6. [http://dx.doi.org/10.1126/science.1252243] [PMID: 25082702]

[32] Bhullar B-A, MarugA n-LobA3n J, Racimo F, et al. Birds have paedomorphic dinosaur skulls. Nature 2012; $487(7406)$ : $223-6$. [http://dx.doi.org/10.1038/nature11146] [PMID: 22722850]

[33] Milner AR. Cosesaurus---the last proavian? Nature 1985; 315: 544. [Date published]. [http://dx.doi.org/10.1038/315544a0]

[34] Hwang SH, Norell MA, Gao K. New specimens of Microraptor zhaoianus (Theropoda: Dromaeosauridae) from northeastern China. Am Mus Novit 2002; 3381: 1-44. [http://dx.doi.org/10.1206/0003-0082(2002)381<0001:NSOMZT >2.0.CO;2]

[35] De Beer G. The evolution of ratites. Bull Br Mus 1954; 4: 59-70. [Nat Hist].

[36] Chiappe LM. Glorified dinosaurs. New York: John Wiley and Sons 2007.

[37] Livezey BC, Zusi RL. Higher-order phylogeny of modern birds (Theropoda, Aves: Neornithes) based on comparative anatomy. II. Analysis and discussion. Zool J Linn Soc 2007; 149(1): 1-95. [http://dx.doi.org/10.1111/j.1096-3642.2006.00293.x] [PMID: 18784798]

[38] McCracken KG, Harshman J, McClellan DA, Afton AD. Data set incongruence and correlated character evolution: an example of functional convergence in the hind-limbs of stifftail diving ducks. Syst Biol 1999; 48(4): 683-714. [http://dx.doi.org/10.1080/106351599259979] [PMID: 12066296]

[39] Hackett SJ, Kimball RT, Reddy S, et al. A phylogenomic study of birds reveals their evolutionary history. Science 2008; 320(5884): 1763-8. [http://dx.doi.org/10.1126/science.1157704] [PMID: 18583609]

[40] Sorenson MD, Cooper A, Paxinos EE, et al. Relationships of the extinct moa-nalos, flightless Hawaiian waterfowl, based on ancient DNA. Proc Biol Sci 1999; 266(1434): 2187-93.

[http://dx.doi.org/10.1098/rspb.1999.0907] [PMID: 10649633]

[41] Murray PF, Megirian D. The skull of dromornithid birds: anatomical evidence for their relationship to Anseriformes (Dromornithidae, Anseriformes). Rec S Aust Mus 1998; 31: 51-97.

[42] Cracraft J. Continental drift, paleoclimatology, and the evolution and biogeography of birds. J Zool 1973; 169: 455-545. [http://dx.doi.org/10.1111/j.1469-7998.1973.tb03122.x] 
[43] Cracraft J. Avian evolution, Gondwana biogeography and the Cretaceous-Tertiary mass extinction event. Proc Biol Sci 2001; 268(1466): $459-69$. [http://dx.doi.org/10.1098/rspb.2000.1368] [PMID: 11296857]

[44] Organ CL, Shedlock AM, Meade A, Pagel M, Edwards SV. Origin of avian genome size and structure in non-avian dinosaurs. Nature 2007; 446(7132): $180-4$ [http://dx.doi.org/10.1038/nature05621] [PMID: 17344851]

[45] Organ CL, Shedlock AM. Palaeogenomics of pterosaurs and the evolution of small genome size in flying vertebrates. Biol Lett 2009; 5(1): 47-50. [http://dx.doi.org/10.1098/rsbl.2008.0491] [PMID: 18940771]

[46] Mayr G. Avian higher-level phylogeny: well-supported clades and what we can learn from a phylogenetic analysis of 2954 morphological characters. J Syst Evol Res 2007; 46(1): 63-72.

[47] Gingerich P. cladistic futures. Nature 1998; 336: 628. [http://dx.doi.org/10.1038/336628a0]

[48] Nesbitt SJ. The anatomy of Effigia okeeffeae (Archosauria, Suchia), theropod-like convergence, and the distribution of related taxa. Bull Am Mus Nat Hist 2007; 302: 1-84

[http://dx.doi.org/10.1206/0003-0090(2007)302[1:TAOEOA]2.0.CO;2]

[49] Zanno LE, Drymala S, Nesbitt SJ, Schneider VP. Early crocodylomorph increases top tier predator diversity during rise of dinosaurs. Sci Rep 2015; 5: 9276 [http://dx.doi.org/10.1038/srep09276] [PMID: 25787306]

[50] Chatterjee S. Postosuchus, a new thecodontian reptile from the Triassic of Texas and the origin of tyrannosaurs. Phil Trans Royal Soc, ser B 1985; 332: 277-342. [http://dx.doi.org/10.1098/rstb.1991.0056]

[51] Nesbitt SJ, Norell MA. Extreme convergence in the body plans of an early suchian (Archosauria) and ornithomimid dinosaurs (Theropoda). Proc Biol Sci 2006; 273(1590): 1045-8.

[http://dx.doi.org/10.1098/rspb.2005.3426] [PMID: 16600879]

[52] Howgate ME. Back to the trees for Archaeopteryx in Bavaria. Nature 1984; 31: 435-6.

[53] Čapek D, Metschler BT, Müller GB. Thumbs down: A molecular-morphogenetic approach to avian digit homology. J Exp Zool, B. Mol Devel Evol 2013; 322(1): 1-1223.

[54] de Bakker MA, Fowler DA, den Oude K, et al. Digit loss in archosaur evolution and the interplay between selection and constraints. Nature 2013; 500(7463): 445-8. [http://dx.doi.org/10.1038/nature12336] [PMID: 23831646]

[55] Feduccia A, Nowicki J. The hand of birds revealed by early ostrich embryos. Naturwissenschaften 2002; 89(9): 391-3. [http://dx.doi.org/10.1007/s00114-002-0350-y] [PMID: 12435089]

[56] Wagner GP, Gauthier JA. 1,2,3 =2,3,4: a solution to the problem of the homology of the digits in the avian hand. Proc Natl Acad Sci USA 1999; 96(9): 5111-6. [http://dx.doi.org/10.1073/pnas.96.9.5111] [PMID: 10220427]

[57] Zhou Z. The origin and early evolution of birds: discoveries, disputes, and perspectives from fossil evidence. Naturwissenschaften 2004; 91(10): 455-71.

[http://dx.doi.org/10.1007/s00114-004-0570-4] [PMID: 15365634]

[58] Padian K, Chiappe LM. The origin of birds and their flight. Sci Am 1998; 278(2): 38-47. [http://dx.doi.org/10.1038/scientificamerican0298-38] [PMID: 9472492]

[59] Chiappe LM. Climbing Archaeopteryx? A response to Yalden. Archaeopteryx 1997; 15: 109-12.

[60] Davis M. (producer) The four-winged dinosaur. NOVA 2008. [http://www.pbs.org/wgbh/nova/microraptor/], pts. 5 and 2

[61] Xu X, Zhou Z, Wang X, Kuang X, Zhang F, Du X. Four-winged dinosaurs from China. Nature 2003; 421(6921): 335-40. [http://dx.doi.org/10.1038/nature01342] [PMID: 12540892]

[62] Dial KP. Wing-assisted incline running and the evolution of flight. Science 2003; 299(5605): 402-4. [http://dx.doi.org/10.1126/science.1078237] [PMID: 12532020]

[63] Senter P. Scapular orientation in theropods and basal birds, and the origin of flapping flight. Acta Palaeontol Pol 2006; 51: 305-13.

[64] Bock WJ. The furcular and the evolution of avian flight. Paleontol J 2013; 47: 1236-44. [http://dx.doi.org/10.1134/S0031030113110038]

[65] Birn-Jeffery AV, Miller CE, Naish D, Rayfield EJ, Hone DW. Pedal claw curvature in birds, lizards and mesozoic dinosaurs--complicated categories and compensating for mass-specific and phylogenetic control. PLoS One 2012; 7(12): e50555. [http://dx.doi.org/10.1371/journal.pone.0050555] [PMID: 23227184]

[66] Ostrom JH. Archaeopteryx and the origin of flight. Q Rev Biol 1974; 49: 27-47. [http://dx.doi.org/10.1086/407902] 
[67] Yalden DW. Forelimb function in Archaeopteryx. In: Ostrom JH, Viohl JH, Wellnhofer P, Eds. The Beginnings of Birds. Eichstätt, Germany: Freunde Jura Mus 1985; pp. 91-7.

[68] Yalden DW. Climbing Archaeopteryx. Archaeopteryx 1997; 15: 107-8.

[69] Bock WJ. The arboreal theory for the origin of birds. In: Ostrom JH, Viohl JH, Wellnhofer P, Eds The Beginnings of Birds. Eichstätt, Germany: Freunde Jura Mus 1985; pp. 267-77.

[70] Bock WJ. The arboreal origin of avian flight. Mem Cal Acad Sci 1996; 8: 57-72.

[71] Chiappe LM, Ji S, Ji Q, Norell MA. Anatomy and systematics of the Confuciusornithidae. (Theropoda:Aves) from the Late Mesozoic of China. Bull Am Mus Nat Hist 1999; 242: 1-89.

[72] Olson SL. Auk 2000; 117(3): 836-9. [Review of: Anatomy and systematics of the Confuciusornithidae (Theropoda: Aves) from the Late Mesozoic of China].

[73] Ostrom JH. On the origin of birds and of avian flight. In: Prothero DR, Schoch RM, Eds. Major Features of Vertebrate Evolution. Knoxville: University of Tennessee Press 1994; pp. 160-77.

[74] Paul GS. Dinosaurs of the air: The evolution and loss of flight in dinosaurs and birds. Baltimore: Johns Hopkins University Press 2002.

[75] Czerkas SA, Yuan C. An arboreal maniraptoran from northeast China. Dino Mus J 2002; 1: 63-95.

[76] Burnham DA, Feduccia A, Martin LD, Falk AR. Tree climbing ?" a fundamental avian adaptation. J Syst Palaeontology 2011 ; 9(1): 103-7. [http://dx.doi.org/10.1080/14772019.2010.522201]

[77] Feduccia A. Topsy-turvy bird phylogeny. In: Cullum A, Martinus AW, Eds. 52 Things You Should Know About Palaeontology. 2015; pp. 118-9.

[78] Schweitzer MH, Zheng W, Organ CL, et al. Biomolecular characterization and protein sequences of the Campanian hadrosaur B. canadensis. Science 2009; 324(5927): 626-31. [http://dx.doi.org/10.1126/science.1165069] [PMID: 19407199]

[79] Ossa-Fuentes L, Mpodozis J, Vargas AO. Bird embryos uncover homology and evolution of the dinosaur ankle. Nature Comm 2015.

[80] Sereno PC, Arcucci AB. Dinosaur precursors from the Middle Triassic of Argentina: Lagerpeton chanarensis. J Vert Paleo 1994; 13(4): 385-99.

[http://dx.doi.org/10.1080/02724634.1994.10011522]

[81] Sereno PC, Arcucci AB. Dinosaurian precursors from the Middle Triassic of Argentina: Marasuchus lilloensis gen. nov. J Vert Paleo 1994; 14: 53-73. [http://dx.doi.org/10.1080/02724634.1994.10011538]

[82] Nesbitt SJ, Irmis RB, Parker WG, Smith ND, Turner AH, Rowe T. Hindlimb osteology and distribution of basal dinosauromorphs from the Late Triassic of North America. J Vert Paleo 2009; 29(2): 498-516. [http://dx.doi.org/10.1671/039.029.0218]

[83] Wells J. Icons of Evolution. Washington, DC: Regnery 2000.

[84] Popper K. The Myth of the Framework. London: Routledge 1994.

[85] Ji Q, Currie PJ, Norell MA, Ji S-A. Two feathered dinosaurs form northeastern China. Nature 1998; 393: $753-61$. [http://dx.doi.org/10.1038/31635]

[86] Sereno PC. The evolution of dinosaurs. Science 1999; 284(5423): 2137-47. [http://dx.doi.org/10.1126/science.284.5423.2137] [PMID: 10381873]

[87] Elżanowski A. A comparison of the jaw skeleton in theropods and birds, with a description of the palate in the Oviraptoridae. Smithsonian Contr to Paleobiol 1999; 89: 311-23.

[88] Maryańska T, Osmólska H, Wolsan HM. Avialan status for Oviraptosauria. Acta Palaeontol Pol 2002; 47: $97-116$.

[89] Lü J, Dong Z, Azuma Y, Barsbold R, Tomida Y. Oviraptosaurs compared to birds. Proc 5th Symp Soc Avian Paleontol Evol. 175-89.

[90] Gong E-P, Martin LD, Burnham DA, Falk AF, Hou L-h. A new species of Microraptor from the Jehol Biota of northeastern China. Palaeoworld 2012; 21: 81-91. [http://dx.doi.org/10.1016/j.palwor.2012.05.003]

[91] Gee H. Delusions of faith as a science. Nature News 2006 Oct; [http://dx.doi.org/10.1038/news 061023.11]

[92] Huxley TH. Further evidence of the affinity between the dinosaurian reptiles and birds. Proc Geol Soc Lond 1870; $26: 12-31$. [http://dx.doi.org/10.1144/GSL.JGS.1870.026.01-02.08]

[93] Hertel F, Campbell KE Jr. The antitrochanter of birds: form and function in balance. Auk 2007; 124(3): 789-805. [http://dx.doi.org/10.1642/0004-8038(2007)124[789:TAOBFA]2.0.CO;2]

[94] Huxley TH. Letter to E. Haeckel 1874. In: Huxley L, Ed. Life and Letters of Thomas Henry Huxley. London: Macmillan and Company 1900; Vol. 1: p. 303. 
[95] Desmond A. Archetypes and Ancestors: Palaeontology in Victorian London, 1850-75. Chicago: University of Chicago Press 1982.

[96] Feduccia A. A colourful menagerie. [review of Feathered Dinosaurs: The Origin and Evolution of Birds. John Long. Oxford University Press, UK, 2009] Tends Ecol Evol 2009; 24: 415-6.

[97] Owen R. A history of british fossil reptiles. London: Cassell \& Company Ltd. 1849; Vol. I. [http://dx.doi.org/10.5962/bhl.title.7529]

[98] De Beer G. The evolution of ratites. Bull Br Mus 1956; 4: 59-70. [Nat Hist].

[99] Lowe PR. A description of Atlantesia rogersi, the diminutive flightless tail of Inaccessible Island (South Atlantic), with some notes on flightless rails. Ibis 12 ser 1928; 4: 99-131.

[100] Lowe PR. On the relationship of Struthiones to the dinosaurs and to the rest of the avian class, with special reference to the position of Archaeopteryx. Ibis 1935; 5: 398-432.

[101] Simpson GG. Fossil penguins. Bull Am Mus Nat Hist 1946; 87: 1-99.

[102] Foth C, Tischlinger H, Rauhut OW. New specimen of Archaeopteryx provides insights into the evolution of pennaceous feathers. Nature 2014; 511(7507): 79-82. [http://dx.doi.org/10.1038/nature13467] [PMID: 24990749]

[103] Agnolin FL, Novas FE. Avian ancestors A review of the phylogenetic relationships of the theropods Unenlagiidae, Microraptoria, Anchiornis and Scansoriopterygidae. Berlin: Springer Briefs in Earth System Sciences 2013; pp. 1-96.

[104] Chiappe LM. The dinosaur conspiracy. Bioscience 2012; 62(8): 770-2.

[105] Zhou Z, Hou Lh. The discovery and study of Mesozoic birds in China. In: Chiappe LM, Witmer LM, Eds. Mesozoic birds: Above the Heads of the Dinosaurs. Berkeley: University of California Press 2002; pp. 160-83.

[106] Goldberg EE, Igi B. On phylogenetic tests of irreversible evolution. Evolution 2008; 62(11): $2727-41$. [http://dx.doi.org/10.1111/j.1558-5646.2008.00505.x] [PMID: 18764918]

[107] Dodson P. Origin of birds: the final solution. Am Zool 2000; 40(4): 504-12.

[108] Norell MA, Chiappe LM. Flight from reason. In: Review of: The origin and evolution of birds, by A Feduccia Nature. 1996; 384: p. 230. [http://dx.doi.org/10.1038/384230a0]

[109] Padian K. Review of The origin and evolution of birds, by A. Feduccia. In: American Scientific. 1997; vol. 85: pp. 178-80.

[110] Makovicky PJ, Zanno LE. Theropod diversity and refinement of avian characteristics. In: Dyke G, Kaiser G, Eds. Living dinosaurs: The Evolutionary History of Modern Birds. New York: John Wiley \& Sons 2011; pp. 9-29. [http://dx.doi.org/10.1002/9781119990475.ch1]

[111] Chen PJ, Dong ZM, Zheng SN. An exceptionally well preserved theropod dinosaur from the Yixian Formation of China. Nature 1998; 391: 147-52. [http://dx.doi.org/10.1038/34356]

[112] Norell MA, Xu X. Feathered dinosaurs. Annu Rev Earth Planet Sci 2005; 33: 277-99. [http://dx.doi.org/10.1146/annurev.earth.33.092203.122511]

[113] Zhang F, Kearns SL, Orr PJ, et al. Fossilized melanosomes and the colour of Cretaceous dinosaurs and birds. Nature 2010; 463(7284): $1075-8$. [http://dx.doi.org/10.1038/nature08740] [PMID: 20107440]

[114] Lingham-Soliar T. The evolution of the feather: Sinosauropteryx, a colourful tail. J Ornithol 2011; $152(3)$ : 567-77. [http://dx.doi.org/10.1007/s10336-010-0620-y]

[115] Lingham-Soliar T. The Vertebrate integument. In: structure, design and function. Heidleberg, Germany: Springer $2015 ; 2$.

[116] Clarke J. Feathers before flight. Science 2013; 340(6133): 690-2. [http://dx.doi.org/10.1126/science.1235463] [PMID: 23661746]

[117] Barrett PM, Evans DC, Campione NE. Evolution of dinosaur epidermal structures. Biol Lett 2015; $11(6): 20150229$. [http://dx.doi.org/10.1098/rsbl.2015.0229] [PMID: 26041865]

[118] Lingham-Soliar T, Feduccia A, Wang X. A new Chinese specimen indicates that 'protofeathers' in the Early Cretaceous theropod dinosaur Sinosauropteryx are degraded collagen fibres. Proc Biol Sci 2007; 274(1620): 1823-9. [http://dx.doi.org/10.1098/rspb.2007.0352] [PMID: 17521978]

[119] Zhang F, Kearns SL, Orr PJ, et al. Fossilized melanosomes and the colour of Cretaceous dinosaurs and birds. Nature 2010; 463(7284): 1075-8. [http://dx.doi.org/10.1038/nature08740] [PMID: 20107440]

[120] Clarke JA, Ksepka DT, Salas-Gismondi R, et al. Fossil evidence for evolution of the shape and color of penguin feathers. Science 2010; 330(6006): 954-7. [http://dx.doi.org/10.1126/science.1193604] [PMID: 20929737]

[121] Li Q, Clarke JA, Gao KQ, et al. Melanosome evolution indicates a key physiological shift within feathered dinosaurs. Nature 2014; 507(7492): 350-3. 
[http://dx.doi.org/10.1038/nature12973] [PMID: 24522537]

[122] Vinther J, Briggs DE, Prum RO, Saranathan V. The colour of fossil feathers. Biol Lett 2008; 4(5): 522-5. [http://dx.doi.org/10.1098/rsbl.2008.0302] [PMID: 18611841]

[123] Moyer AE, Zheng W, Johnson EA, et al. Melanosomes or microbes: testing an alternative hypothesis for the origin of microbodies in fossil feathers. Sci Rep 2014; 4: 4233. [http://dx.doi.org/10.1038/srep04233] [PMID: 24595214]

[124] Lindgren J, Moyer A, Schweitzer MH, et al. Interpreting melanin-based coloration through deep time: a critical review. Proc Biol Soc 2015; 282(1813)

[http://dx.doi.org/10.1098/rspb.2015.0614]

[125] Manning PL, Edwards NP, Wogelius RA, et al. Synchrotron-based chemical imaging reveals plumage patterns in a 150 million year old early bird. J Anal At Spectrom 2013; 28(7): 1024-30. [http://dx.doi.org/10.1039/c3ja50077b]

[126] Diamond J, Robinson JA. All the world's a lab. New Sci 2010; 28-31. [http://dx.doi.org/10.1016/S0262-4079(10)60720-8]

[127] Avise J. Cladists in wonderland On evolution. 103-6. [http://dx.doi.org/10.1111/j.0014-3820.2000.tb00728.x]

[128] Schopenhauer A. Die Welt als Wille und Vorstellung 1818 (English translation by Payne EFJ), in The World as Will and Representation . Colorado: Falcon's Wing Press 1958.

[129] Olson SL. [Review of] New Perspectives on the Origin and Early Evolution of Birds. Proceeding International Symposium in Honor of John H. Ostrom. In: Gauthier J, Gall LF, Eds. Auk 2003; 119(4): 1202-5. [http://dx.doi.org/10.2307/4090253]

(C) Alan Feduccia; Licensee Bentham Open.

This is an open access article licensed under the terms of the Creative Commons Attribution-Non-Commercial 4.0 International Public License (CC BY-NC 4.0) (https://creativecommons.org/licenses/by-nc/4.0/legalcode), which permits unrestricted, non-commercial use, distribution and reproduction in any medium, provided the work is properly cited. 